\title{
Radioprotective effects of oral 17-dimethylaminoethylamino-17- demethoxygeldanamycin in mice: bone marrow and small intestine
}

\author{
Xinyue Lu ${ }^{1^{*}}$, Dilber Nurmemet ${ }^{1}$, David L Bolduc ${ }^{1}$, Thomas B Elliott ${ }^{1}$ and Juliann G Kiang ${ }^{1,2,3}$
}

\begin{abstract}
Background: Our previous research demonstrated that one subcutaneous injection of 17-Dimethylaminoethylamino-17demethoxygeldanamycin (17-DMAG) 24 hours (h) before irradiation (8.75 Gy) increased mouse survival by 75\%. However, the protective mechanism of 17-DMAG is currently unknown. The present study aimed to investigate whether oral administration of 17-DMAG was also radioprotective and the potential role it may play in radioprotection.

Results: A single dose of orally pre-administered $(24,48$, or 72 h) 17-DMAG (10 mg/kg) increased irradiated mouse survival, reduced body weight loss, improved water consumption, and decreased facial dropsy, whereas orally post-administered 17-DMAG failed. Additional oral doses of pre-treatment did not improve 30-day survival. The protective effect of multiple pre-administrations (2-3 times) of 17-DMAG at $10 \mathrm{mg} / \mathrm{kg}$ was equal to the outcome of a single pre-treatment. In 17-DMAG-pretreated mice, attenuation of bone marrow aplasia in femurs 30 days after irradiation with recovered expressions of cluster of differentiation 34, 44 (CD34, CD44), and survivin in bone marrow cells were observed. 17-DMAG also elevated serum granulocyte-colony stimulating factor (G-CSF), decreased serum fms-related tyrosine kinase 3 ligand, and reduced white blood cell depletion. 17-DMAG ameliorated small intestinal histological damage, promoted recovery of villus heights and intestinal crypts including stem cells, where increased leucine-rich repeat-containing G-protein coupled receptor 5 (Lgr5) was found 30 days after irradiation.
\end{abstract}

Conclusions: 17-DMAG is a potential radioprotectant for bone marrow and small intestine that results in survival improvement.

Keywords: Radiation, Survival, 17-DMAG, Bone marrow, Stem cell, Intestine, Lgr5, Survivin, G-CSF, Mice

\section{Background}

17-dimethylamino-ethylamino-17-demethoxygeldanamycin (17-DMAG) was a derivative of heat shock protein 90 (Hsp90) inhibitor geldanamycin [1,2]. Compared to geldanamycin, 17-DMAG was greater water-soluble and lower hepatotoxic [3], and was distributed more rapidly in tissues. These advantages led to superior clinical applications in human tumor therapy $[4,5]$. Human cancer studies [6,7] showed the mean half-life of 17-DMAG to be 22.3-24 $\mathrm{h}$, which was much longer than

\footnotetext{
* Correspondence: xinyue.lu.ctr@usuhs.edu

${ }^{1}$ Radiation Combined Injury Program, Scientific Research Department, Armed Forces Radiobiology Research Institute, 8901 Wisconsin Avenue, Bethesda, MD 20889-5603, USA

Full list of author information is available at the end of the article
}

what has been previously observed in mice (69-88 min) after an intravenous (i.v.) injection [8]. The drug was well tolerated over periods of months of use even when combined with other medical treatments such as radiation therapy $[4,9]$. In vitro, 17-DMAG selectively killed human tumor cells by chelating Hsp90 in its high-affinity conformation, which existed only in cancer cells [10], and thereby prevented mutant proteins from entering the nucleus to trigger gene activation [11]. Because of the roles that Hsp90 played in key processes of tumor growth and development, including induction and stabilization of growth factors and other signals in transformed cells, angiogenesis, and promotion of metastasis, Hsp90 understandably became

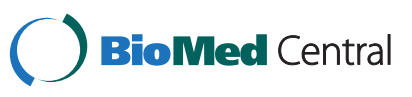


an inviting target in the search for pharmaceutical agents to kill cancer cells.

Recent reports from our laboratory revealed that 17-DMAG protected human T-cells and normal healthy peripheral blood mononuclear cells from $\gamma$-photon radiation in vitro and ex vivo $[12,13]$. The protective effects were associated with inhibiting inducible nitric oxide synthase (iNOS)/caspase-3 cascade [12] and protein 53 (p53) accumulations [13] to prevent apoptosis in irradiated cells. Those results imply that Hsp90 inhibitors such as 17-DMAG could be useful not only for cancer therapy, but also for general radioprotection for normal healthy tissues. 17-DMAG was, therefore, considered as a candidate radioprotectant for total-body irradiation countermeasure in vivo.

Total-body exposure to ionizing radiation in humans and animals results in multiple organ injury and dysfunction. Ionizing radiation injured hematopoietic, gastrointestinal, or cerebrovascular systems depend on the total dose of radiation received $[14,15]$. Safe and effective radioprotectors were needed in the event of a radiological warfare or accident, a nuclear terrorist attack, radiation therapy, or prolonged space travel [14-18].

Our previous data demonstrated the potential of 17-DMAG as a radioprotector. A subcutaneous (s.c.) injection of a single dose of 17-DMAG $(25 \mathrm{mg} / \mathrm{kg})$ given to CD2F1 mice $24 \mathrm{~h}$ before a lethal dose of gamma-radiation at 8.75 Gy (i.e., $\mathrm{LD}_{70 / 30}$, a dose resulting in $70 \%$ of exposed population died within 30 days in a study [19]) improved mouse 30-day survival by 75 percentage points with a dose reduction factor (DRF) of 1.2 [20]. However, oral administration of prophylactic or therapeutic drugs is a most desirable and feasible remedy of prevention or treatment in civilian and military mass radiation casualties from a radiation accident, or fist responders entering radiation contaminated areas. It is, therefore, of great interest to determine whether orally administered 17-DMAG was also radioprotective for survival, bone marrow, and small intestine. We hypothesized that 17-DMAG given orally would provide radioprotection but, possibly, at various levels of effectiveness in comparison to s.c. administration. In this study, we investigated the radioprotective efficacy and possible underlying mechanisms of 17-DMAG when it was administered orally in mice prior to ionizing irradiation. This is the first report that orally administered 17-DMAG provided prophylactic reduction of ionizing radiation-induced lethality, bone marrow damage, and small intestine injury in CD2F1 mice. This radioprotective activity was demonstrated in (1) partially preventing bone marrow cell damage with the consequence of upregulated granulocyte-colony stimulating factor (G-CSF) in serum, decreased fms-like tyrosine kinase-3 (Flt-3) ligand in serum, and increased survivin expression in bone marrow cells, which may further promote bone marrow recovery, and (2) ameliorating the radiation-induced injury in small intestinal crypt cells perhaps by increased leucine-rich repeat-containing G-protein coupled receptor 5 (Lgr5)-positive crypt cells, which may accelerate villus repairing and recovery 30 days post-irradiation.

\section{Results}

Orally administered 17-DMAG prior to irradiation increased mouse survival

Mice received a single oral dose of $5,10,25$, or $75 \mathrm{mg} / \mathrm{kg}$ 17-DMAG 24 h before irradiation at 8.75 Gy (i.e. $L D_{75 / 30}$ ). In vehicle-treated mice, radiation-induced mortality started at day 9 after irradiation and the 30-day survival was 33.5\% (Figure 1A). A single oral dose of $10 \mathrm{mg} / \mathrm{kg}$ 17-DMAG protected $56.3 \%$ of mice from radiation-induced mortality. The onset of mortality began at $11.6 \mathrm{~d}, 2.5$ days later than the vehicle-treated mice $(11.625 \pm 0.296$ vs. $9.125 \pm 0.5625$, $\mathrm{p}<0.05, \mathrm{n}=4$ repeated experiments) after irradiation and prolonged the time to reach $50 \%$ survival $\left(\mathrm{ST}_{50}\right)$ approximately by 8 days $(\geq 25.25 \pm 2.75$ vs. $17.00 \pm 0.89, p<0.05$, $\mathrm{n}=4$ repeated experiments). The dose-modifying factor (DMF) [18] for oral administration of 17-DMAG $24 \mathrm{~h}$ before irradiation (ratio of survival of animals treated with 17-DMAG to survival of the untreated animals) was $56.3 / 33.5=1.68$. However, pretreatment with oral doses of 5,25 , and $75 \mathrm{mg} / \mathrm{kg}$ did not improve mouse 30-day survival after irradiation (data not shown), suggesting a narrow effective dose range via oral route in irradiated CD2F1 mouse. 17-DMAG administered alone up to $75 \mathrm{mg} / \mathrm{kg}$ without irradiation did not cause mortality in sham animals (data not shown).

\section{7-DMAG induced radioprotection for up to three days before irradiation}

The optimal oral administration time was determined at the dose of $10 \mathrm{mg} / \mathrm{kg}$ of 17 -DMAG as shown in Figure 1A-D, oral administration of 17-DMAG 24, 48, or $72 \mathrm{~h}$ before irradiation appeared to increase mouse survival 20-25 percentage points above the corresponding vehicle-treated group $(\mathrm{p}<0.001)$. When the same dose of 17-DMAG was given orally $-1 \mathrm{~h}$, however, no any survival improvement was found.

\section{Multiple oral administrations of 17-DMAG induced the same radioprotective efficacy as a single administration} Multiple oral administrations with 17-DMAG did not further increase its radioprotective efficacy (Figure 2). The percentage of survival in mice given a dose of $10 \mathrm{mg} / \mathrm{kg}$ 17-DMAG 2 or 3 times before irradiation was similar to the survival percentage observed in mice treated with a single dose of 17-DMAG (compared to Figure 1B). However, 17-DMAG given 5 times did not improve survival 


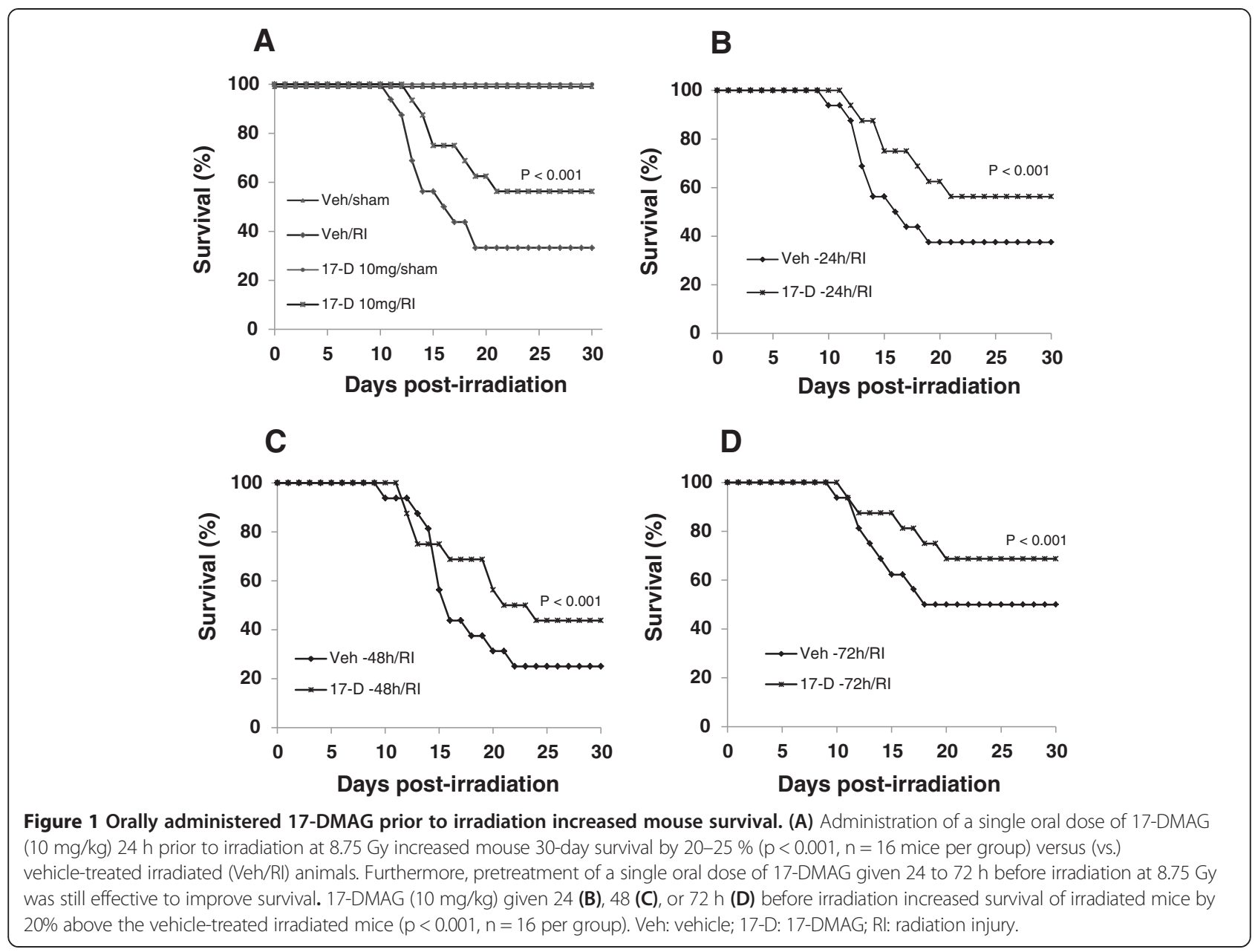

compared with irradiated animals pretreated with 5 times of vehicle.

\section{Oral administration of 17-DMAG after irradiation did not increase survival}

To determine if a single oral dose of 17-DMAG was capable of producing therapeutic efficacy, mice received $10 \mathrm{mg} / \mathrm{kg}$ 17-DMAG orally, 1, 6, or $24 \mathrm{~h}$ after irradiation. All oral administrations of 17-DMAG post-irradiation failed to improve survival (data not shown).

\section{7-DMAG attenuated body weight loss, promoted} recovery of reduced water consumption, and decreased facial dropsy after irradiation

Based on the above results, mice received a single dose of $10 \mathrm{mg} / \mathrm{kg}$ 17-DMAG $24 \mathrm{~h}$ prior to irradiation in the following experiments to investigate changes in body weight, water consumption, and facial dropsy. Irradiation reduced body weights and water consumption [21], but did not induce facial edema in B6D2F1/J mice. As shown in Figure 3A, in CD2F1 mice, irradiation began to reduce the body weight at day 5 and remained low. Irradiation made mice consume less water from day 1 through day 5 . On day 6 the mice increased their water intake that returned to the baseline on day 7 (Figure 3B). Irradiation insult also induced facial dropsy, which began to occur approximately at day 10 (Figure 3C) and seemed to be one of animal moribund signs in this strain. Compared to vehicle group, 17-DMAG administration significantly prevented the radiation-induced loss of body weights during days 15 to 30 (Figure 3A), ameliorated a reduction of water consumption at days 1,3 , 5 , and 6 (Figure 3B). It may be inferred that administration of this drug provided some degree of protection from gastrointestinal injury or dysfunction after irradiation. In addition, an attenuation of facial dropsy was observed at day 15 postirradiation in animals pretreated with 17-DMAG. At day 20 after irradiation, no significant differences of facial dropsy were observed between vehicle- and 17-DMAG-treated surviving mice (Figure 3C).

\section{7-DMAG attenuated bone marrow damage after} irradiation

Mice that received a single oral dose of $10 \mathrm{mg} / \mathrm{kg}$ 17-DMAG $24 \mathrm{~h}$ prior to irradiation were also used to investigate 

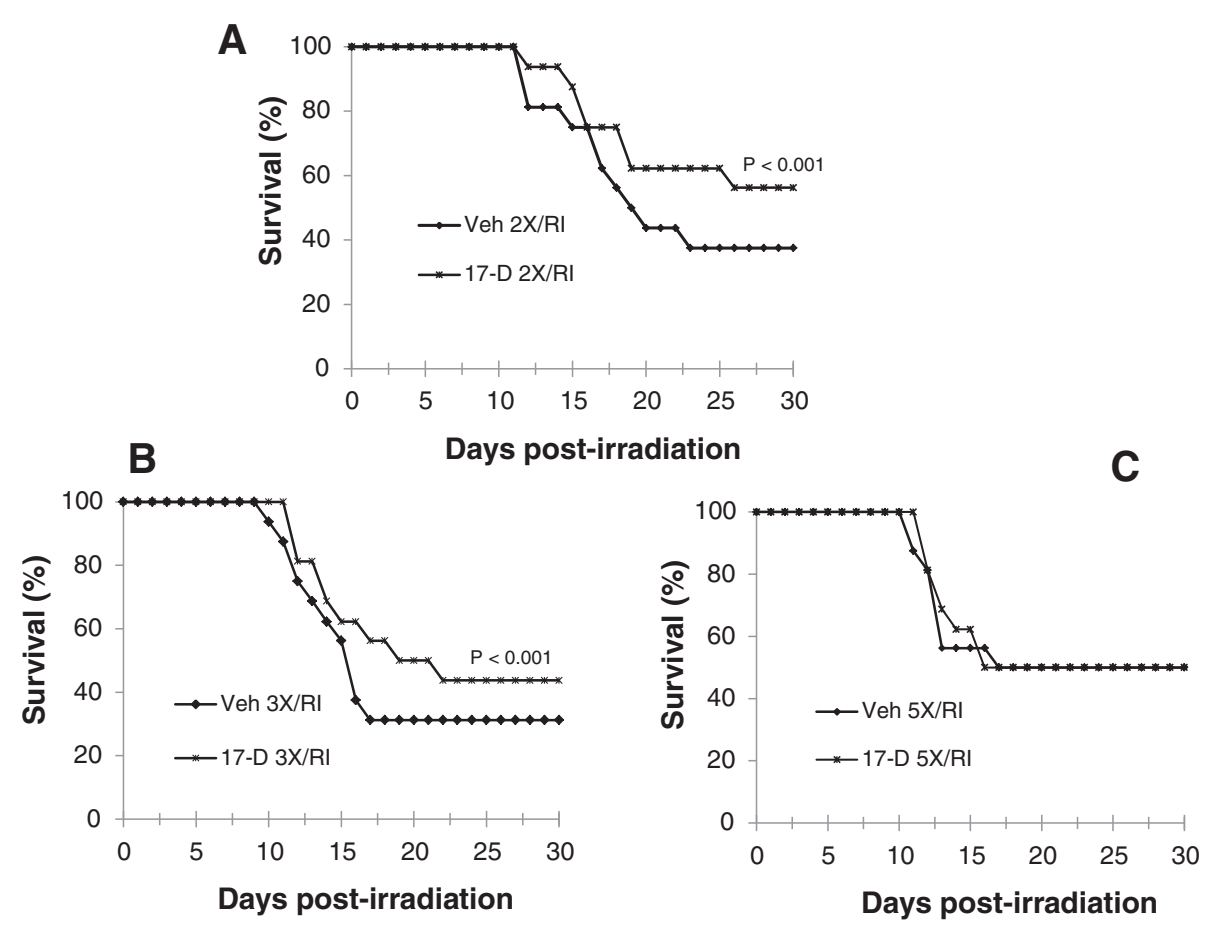

Figure 2 Multiple oral administrations of 17-DMAG induced a similar radioprotective efficacy to a single administration. (A) 17-DMAG $(10 \mathrm{mg} / \mathrm{kg}$ ) or vehicle was given twice $(2 \times)$ at -48 and $-24 \mathrm{~h}$, (B) given three times ( $3 \times)$ at $-72,-48$, and $-24 \mathrm{~h}$, or (C) given five times (5x) at $-120,-96,-72,-48$, and $-24 \mathrm{~h}$ prior to irradiation at 8.75 Gy ( $N=16$ mice per group). Veh: vehicle; 17-D: 17-DMAG; RI: radiation injury.

selected cellular and molecular changes in order to elucidate the protective mechanism.

Bone marrow was examined for its morphological and molecular alterations in surviving mice on the 30th day postirradiation. Pathological changes in sections of femoral bone marrows showed that irradiation reduced marrow cellularity, thereby resulting in the absence of erythroid, rare myeloid and megakaryocytic cells. Many fat vacuoles appeared when stem cells and their lineages, especial megakaryocytes were depleted in the bone marrow (Figure 4C vs. A and B). In contrast, microfoci were regenerated partially (Figure 4D vs. C), megakaryocytes were restored significantly (Figure 4E), and adipogenesis was reduced after 17-DMAG administration (Figure 4F).

A separate experiment was performed in order to determine the effects of 17-DMAG on the survival of bone marrow cells in irradiated mice. Bone marrow cells were collected from femora at days 3, 7 and 15 after irradiation and total live bone marrow cells from each murine femora were determined by trypan blue staining. Gamma-irradiation induced cell death with a significant reduction of total live cell numbers in femora at all three time points. Although 17-DMAG did not significantly improve the bone marrow cell viability at day 3 compared to irradiated vehicle-treated animals, 17-DMAG did markedly promote bone marrow cell viability at day 7 (17-DMAG/RI vs. vehicle/RI: $6.36 \pm 1.75 \times 10^{5}$ vs. $\left.2.0 \times 10^{5} \pm 2.48 \times 10^{4}\right)$ and day $15\left(8.26 \pm 1.84 \times 10^{5}\right.$ vs. $3.46 \times 10^{5} \pm 2.91 \times 10^{4}$ ) after irradiation (Figure $5 \mathrm{~A}$ ). Using a flow cytometric assay, it was determined that 17-DMAG increased bone marrow cell survival with a greater percentage of 7-aminoactinomycin D (7AAD, a death marker of cells) negative cells (Figure 5B left); their average 7AAD-negative percentages in two groups of 17-DMAG/RI and Veh/RI mice (Figure $5 \mathrm{~B}$ right) were $72.77 \pm 7.17 \%$ and $44.2 \pm 4.94 \%(\mathrm{p}<0.01, \mathrm{n}=3)$, respectively, at day 15 after irradiation. The consistent results from both methods indicate that 17-DMAG protects bone marrow cells from irradiation, suggesting the improved bone marrow cell viability may contribute to increased 30-day survival in irradiated mice pretreated with 17-DMAG.

\section{7-DMAG attenuated radiation-induced reduction of CD34 and CD44 expression in bone marrow cells}

CD34 and CD44 are expressed in bone marrow cells. To further verify the detrimental effects of irradiation on bone marrow cells, CD34 and CD44 were measured using Western blotting 30 days postirradiation. We found that irradiation reduced the expression of both CD34 and CD44, which was prevented by 17-DMAG pre-treatment (Figure 5C). Although CD34 and 44 are not specific markers, both are usually expressed in/on hematopoietic, mesenchymal stem cells, and other types 

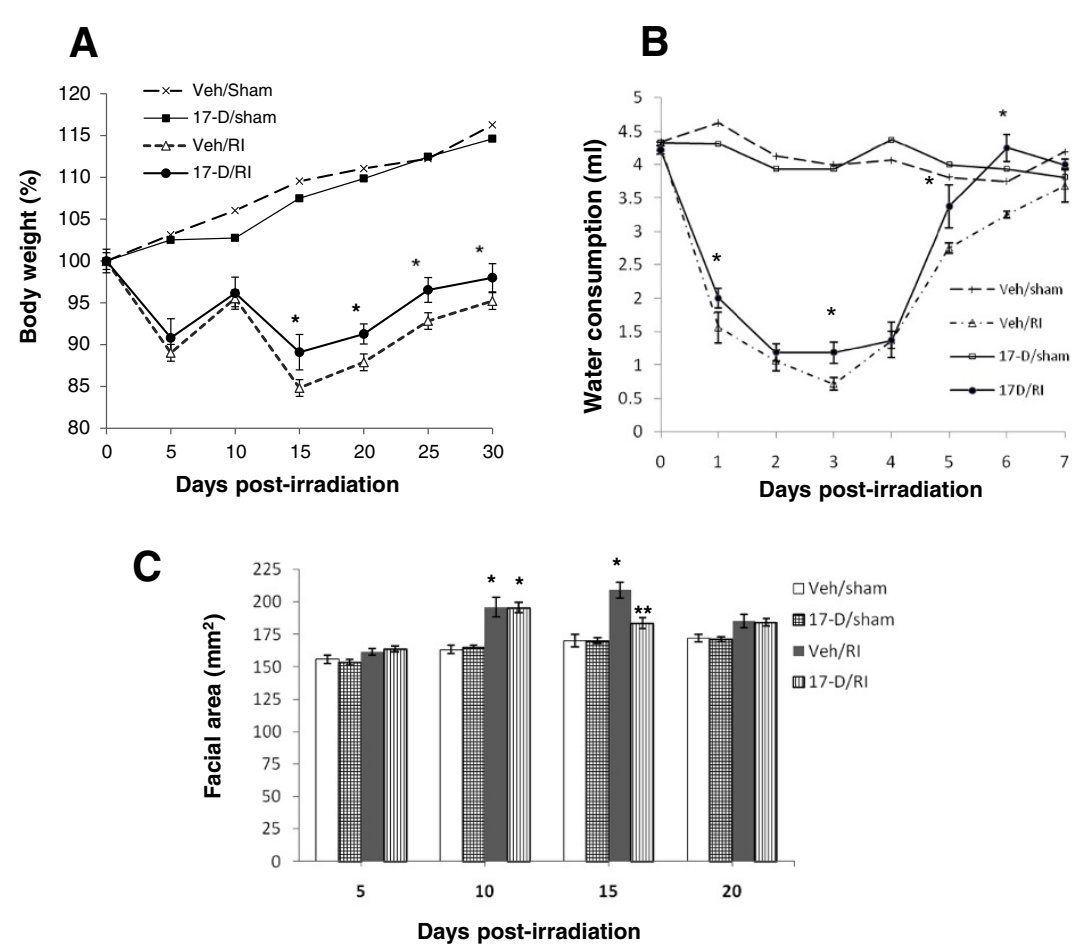

Figure 3 17-DMAG attenuated body weight loss and promoted recovery of reduced water consumption as well as facial dropsy. Mice were orally administered with $10 \mathrm{mg} / \mathrm{kg}$ 17-DMAG or vehicle $24 \mathrm{~h}$ prior to irradiation at $8.75 \mathrm{~Gy}$ ( $\mathrm{N}=16$ mice per group). Their body weights and facial dropsy were monitored for 30 days. Water consumption was measured daily for the first 7 days. (A) Attenuation of body-weight loss during days 15 to 30 after irradiation, ${ }^{*} p=0.03$ vs. Veh/Rl. Error bars indicate the standard error of the mean (SEM) for 5-16 mice per group at different days. (B) Improvement of water consumption at days 1, 3, 5, and 6 during the first 7 days after irradiation, ${ }^{*} p=0.03$ vs. Veh/RI group. Error bars indicate the standard error of the SEM for 16 mice per group at different days. (C) Murine facial area at days 5, 10, 15, and 20 after irradiation. At day 10, ${ }^{*} p<0.01$ vs. Veh/sham and 17-D/sham, and error bars indicate the SEM for 13-16 mice per group; at day 15, * $p<0.01 \mathrm{vs.} \mathrm{Veh/sham,} \mathrm{17-D/sham,}$ and 17-D/Rl; ** $p<0.001$ vs. Veh/RI, error bars indicate the SEM for 9-16 mice per group. Veh: vehicle; 17-D: 17-DMAG; Rl: radiation injury.

of cells in bone marrow. The improved expression of CD34 and 44 after irradiation by 17-DMAG treatment may reflect recovery of total bone marrow cells. Those data reinforced the idea that 17-DMAG protects bone marrow cells 30 days postirradiation.

\section{7-DMAG increased survivin production in bone marrow cells after irradiation}

Survivin is one of several anti-apoptotic proteins. It is over-produced in tumor cells and fetal tissue. Survivin is, however, expressed in normal proliferating adult cells, including human hematopoietic stem cells, T-lymphocytes, and erythroid cells throughout their maturation. It manifests its anti-apoptotic effects by inhibiting various caspases and also uniquely promotes cell mitosis and proliferation [22-24]. Inducible deletion of survivin leads to the bone marrow ablation with widespread loss of hematopoietic progenitors and rapid mortality [23].

To determine if 17-DMAG protected bone marrow cells through upregulation of survivin expression, survivin protein production in bone marrow cells of mice 30 days postirradiation was assessed using immunoblotting. Both
17-DMAG alone and 17-DMAG combined with irradiation upregulated survivin protein production in bone marrow (Figure 6), but 17-DMAG increased survivin significantly more than vehicle control at day 30 after radiation. Average survivin expression in bone marrow cells of 17-DMAG-treated irradiated animals was over two-fold of its level in bone marrow of vehicle-treated irradiated mice (Figure 6B).

\section{7-DMAG upregulated serum G-CSF after irradiation}

Because G-CSF stimulated growth of hematopoietic stem cells in bone marrow [25], G-CSF in serum was assessed by enzyme-linked immunosorbent assay (ELISA) and immunoblotting analysis 30 days postirradiation. Irradiation (8.75 Gy) increased yet not significantly G-CSF concentration in serum, as compared to vehicle-treated sham-operated groups. 17-DMAG $(10 \mathrm{mg} / \mathrm{kg}$ at $-24 \mathrm{~h})$, however, markedly enhanced the radiation-induced G-CSF in animal serum at day 30 after irradiation. The mean concentration of G-CSF in the irradiated animals pre-treated with 17-DMAG vs. vehicle irradiated group was $747.83 \pm 186.88$ vs. $244.35 \pm 80.40 \mathrm{pg} / \mathrm{ml}$, 

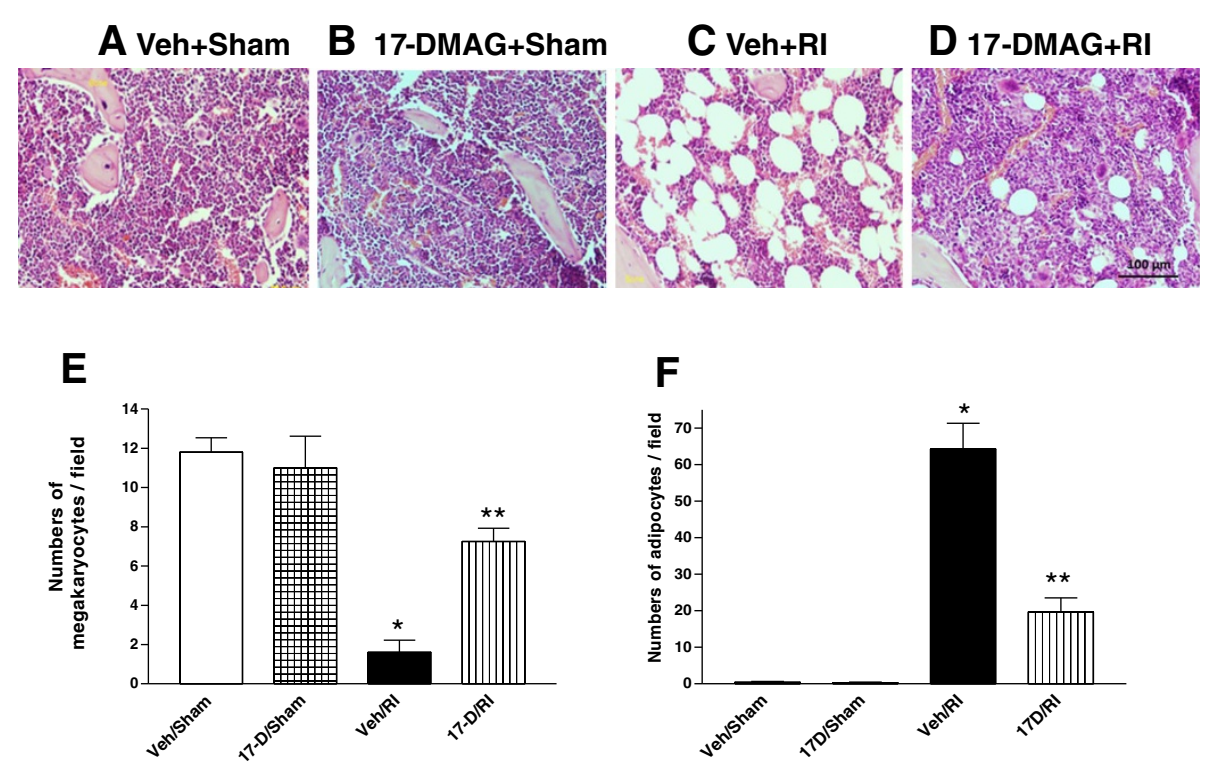

Figure 4 17-DMAG attenuated bone marrow damage after irradiation. Morphological alteration in femur bone marrows of mice pretreated with (A) vehicle + sham, (B) 17-DMAG + sham, (C) vehicle + Rl, and (D) 17-DMAG + Rl 30 days after irradiation at 8.75 Gy. The images were from epiphyseal ends with $\mathrm{H}$ \& E staining, $20 \times$ magnification. A $100 \mu \mathrm{m}$ scale bar was shown on the bottom of right panel D. Radiation induced vast reduction of hematopoietic cellularity and replacement by adipocytes in bone marrow. However, (E) a significantly improved number of megakaryocytes and (F) a significantly decreased numbers of adipocytes were found per field under microscopy $(20 \mathrm{x})$ in bone marrows of 17-DMAG-pretreated mice compared to those in vehicle-pretreated group 30 days after irradiation. ${ }^{*} p<0.001$ vs. Veh/sham, 17-D/sham, and 17-D/Rl; ** $p<0.01$ vs. Veh/Sham, 17-D/sham, and Veh/RI group. Error bars indicate the SEM for at least 4-5 independent experiments. Veh: vehicle; 17-D: 17-DMAG; Rl: radiation injury.

$(\mathrm{p}<0.01$, Figure 7A). Western blot data (data not shown) confirmed the observation obtained using the ELISA method as well.

\section{7-DMAG inhibited radiation-induced increase in Flt-3 ligand in serum and reversed radiation-induced white blood cell (WBC) depletion in blood}

Flt-3 ligand is a bio-indicator for bone marrow aplasia and its release may be triggered by stem cell deficiency in the bone marrow. Its concentration in serum is inversely correlated to the bone marrow integrity $[26,27]$.

In our study, Flt-3 ligand concentration was measured in serum 30 days postirradiation. Irradiation notably increased Flt-3 ligand concentrations $(710.02 \pm 36.94 \mathrm{pg} / \mathrm{ml})$ in serum of irradiated mice treated with vehicle (Figure 7B); whereas 17-DMAG significantly attenuated radiation-induced increase in Flt-3 ligand concentrations $(548.82 \pm 28.83 \mathrm{pg} / \mathrm{ml}$, $\mathrm{p}<0.05)$ in serum. Administration of 17-DMAG alone to sham-treated mice did not alter the baseline of Flt-3 concentration in serum.

To determine the radioprotective effect of 17DMAG on circulating blood cells, peripheral blood was collected and total WBCs were counted manually at day 30. Although radiation reduced numbers of WBCs (in $10^{6}$ cells $/ \mathrm{ml}: 1.09 \pm 0.05$ and $1.93 \pm 0.06$ of vehicle- and 17-DMAG-pretreated irradiated samples vs. $3.88 \pm 0.10$ and $4.23 \pm 0.23$ of both sham controls),
17-DMAG pretreatment increased the number of WBC 1.77 times greater $(p<0.001)$ than the vehicle pretreatment after irradiation (Figure 7C).

\section{7-DMAG had no significant effect on radiation-induced erythropoietin (EPO) increase in serum}

Because EPO produced by kidney and spleen is important for bone marrow cells [28], EPO in serum was measured 30 days after irradiation. Irradiation induced an increased EPO concentration in serum compared to non-irradiated mice (Veh + IR vs. Veh + sham: 175.84 \pm 51.60 vs. $35.80 \pm 7.40 \mathrm{pg} / \mathrm{ml}, \mathrm{p}<0.015)$. However, 17 -DMAG pre-administration did not alter the radiation-induced increase in EPO concentrations compared to irradiated mice pretreated with vehicle (data not shown).

\section{7-DMAG ameliorated intestinal injury induced by irradiation}

To test the protective effect of 17-DMAG against radiationinduced damage of the small intestine by pre-treatment with this drug, histological analysis of the jejunum was performed 30 days post-irradiation. Small intestine of non-irradiated mice showed a histological structure of the villus intestinalis and crypts of Lieberkühn with normal length of villus and healthy crypt cells. In contrast, irradiation induced severe pathological degeneration, which was still observed even 30 days after irradiation. A clear mucosal atrophy, 


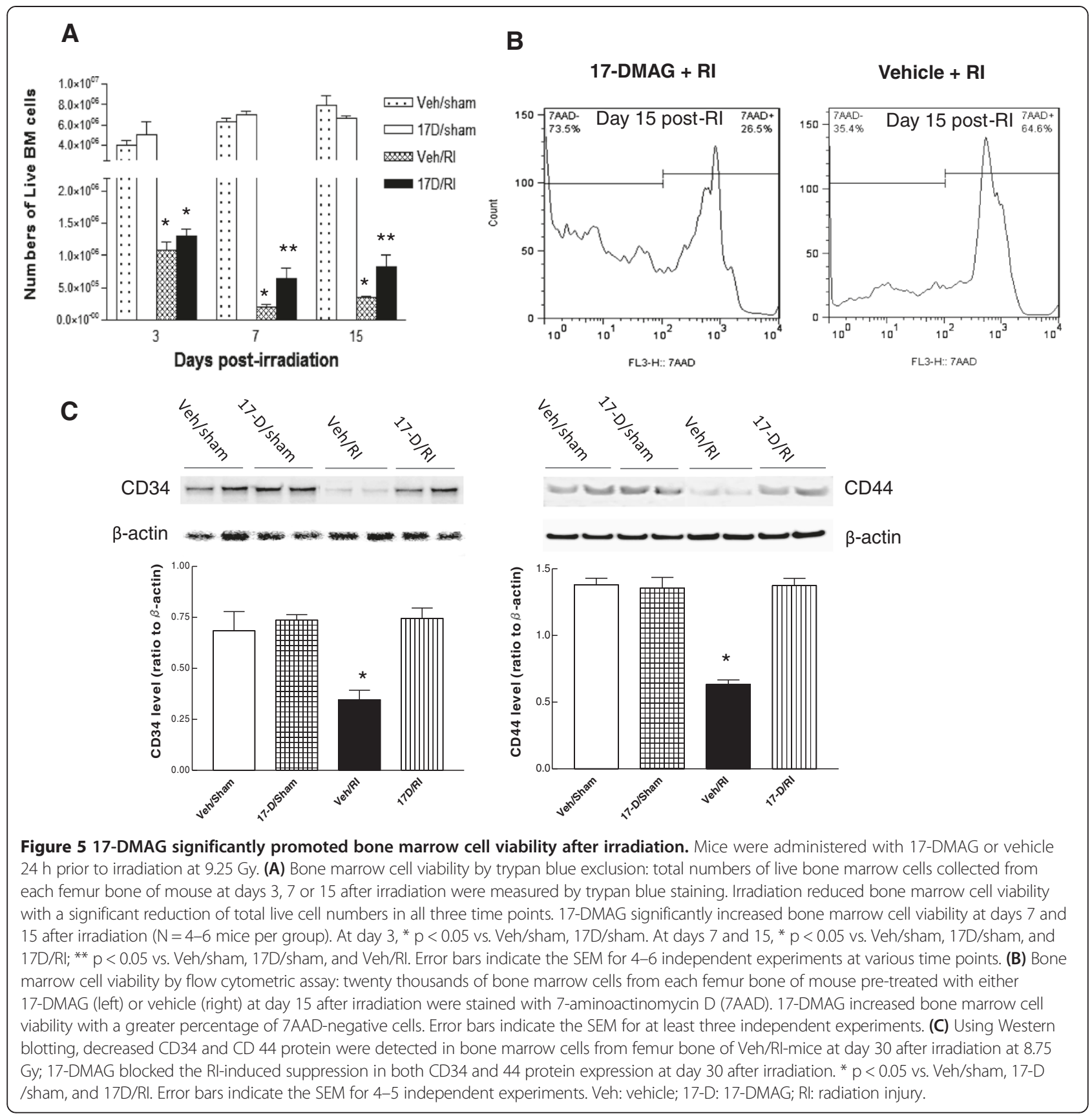

denuded tips of villi were found (Figure $8 \mathrm{C}$ vs. A). In addition, decreased villus heights [29] and crypt numbers [30] in the circumference of intestine were observed at day 30 in surviving irradiated mice with vehicle pretreatment (Figure $8 \mathrm{E}$ and $\mathrm{F}$ ), whereas 17-DMAG pre-treatment markedly improved the radiation-induced degenerative changes in the small intestine. Increased villus lengths (475.00 \pm 15.99 vs. $337.53 \pm 12.12 \mu \mathrm{m}, \mathrm{p}<0.005)$, crypt numbers per circumference $(142.95 \pm 12.79$ vs. $102.00 \pm$ 6.52, $\mathrm{p}<0.0002$ ), and recovered small intestinal morphology in the irradiated mice pre-treated with 17-DMAG significantly differed from vehicle-control mice (Figure 8).

\section{7-DMAG increased small intestinal Lgr5 expression, especially in crypt cells of irradiated mice}

In order to verify whether 17-DMAG has protective effect on small intestinal stem cells (ISC), Lgr5 expression in ISC was measured. Lgr5 was identified as one of markers of ISC. Lgr5-positive intestinal stem cells are crypt base columnar (CBC) cells [31] that intersperse between Paneth 

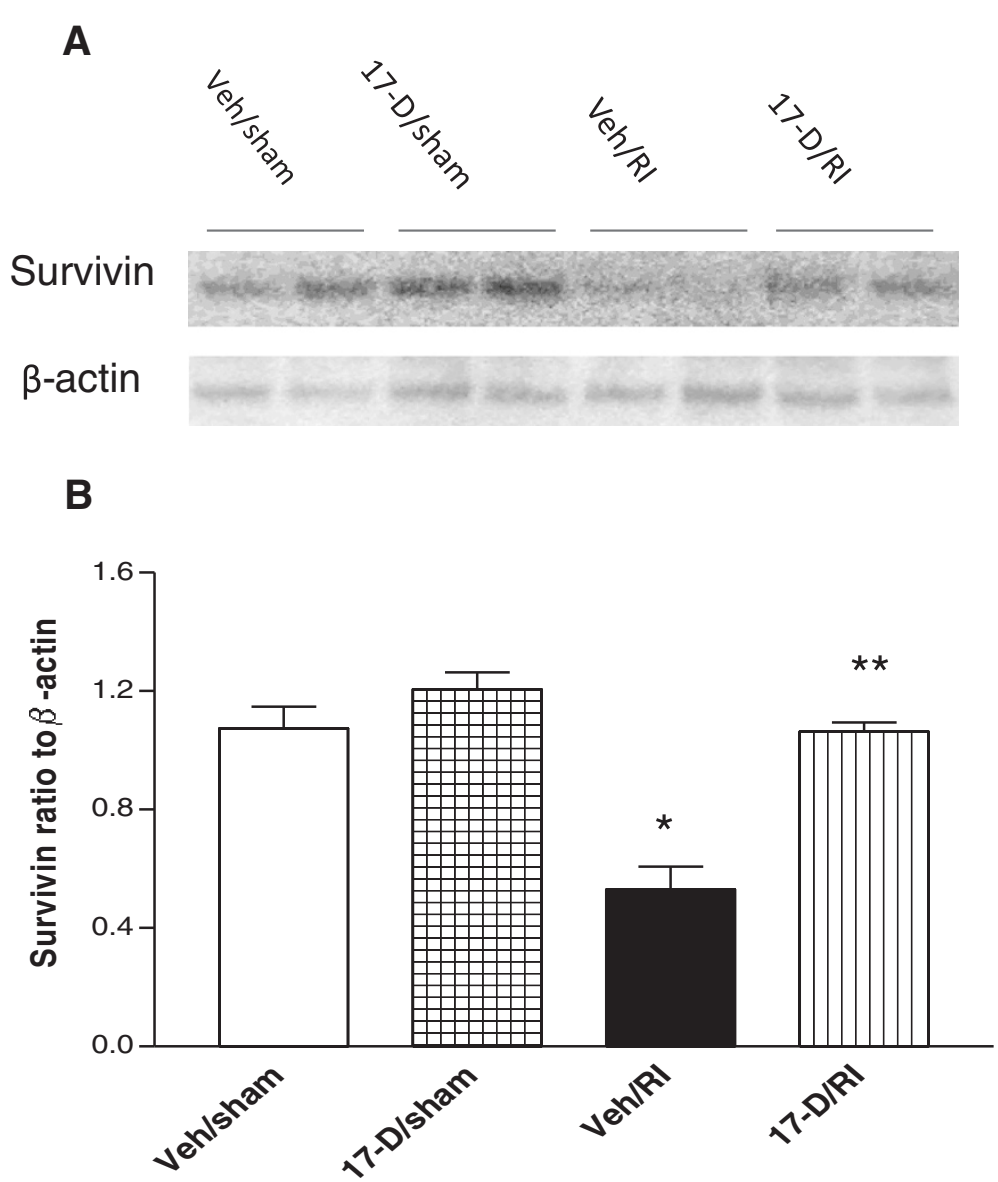

Figure 6 17-DMAG increased survivin protein in bone marrow cells after irradiation. Bone marrow cells were collected from femur bones and analyzed using Western blot for its survivin expression 30 days after irradiation at 8.75 Gy. (A) A representative Western blot of survivin. (B) Densitometric quantitation of survivin protein.* $p<0.01$ vs. Veh/sham, 17-D/sham, and 17D/Rl groups; ${ }^{* *} p<0.001$ vs. Veh/Rl groups. Error bars indicate the SEM for at least four independent experiments. Veh: vehicle; 17-D: 17-DMAG; RI: radiation injury.

cells and express throughout the crypts of the intestine. Irradiation at a high dose induced ISC damage or death with a dramatic ablated Lgr5, which was observed 2 days after irradiation in murine crypt cells [32]. Herein, irradiation resulted in a decrease in the Lgr5 expression in small intestine even at day 30 after irradiation. In comparison, 17-DMAG pretreatment enhanced intestinal Lgr5 level in irradiated mice using western blot analysis (Figure 9A). The density of Lgr5 in jejunum of 17-DMAG pretreated irradiated mice was 3.34 fold $(0.87 \pm 0.18$ vs. $0.26 \pm 0.08, \mathrm{p}<0.01)$ of that in vehicle-pretreated irradiated mice (Figure 9B). Furthermore, the increased Lgr 5 was located at the base of the crypt cells using immunostaining and confocal laser microscope (Figure 9C), indicating the presence of more Lgr5-positive ISC in crypts.

\section{Discussion}

We investigated whether 17-DMAG attenuated radiation injury in bone marrow cells and the small intestine, including ISC. Although previous studies demonstrated significantly increased radiation sensitivity of tumor cells in vivo [4] and in vitro [33] in the presence of 17-DMAG, the radiosensitivity of normal fibroblasts was not altered by Hsp90 inhibition [34], suggesting that the radiosensitization induced by 17-DMAG is tumor-specific. Therefore, 17-DMAG could sensitize tumors while protecting normal tissues from radiation-induced injury or ischemia-induced infarction [34-36]. Our recent studies [13] support the idea that 17-DMAG provides protection for normal human peripheral blood mononuclear cells from irradiation.

In the present study, orally administered 17-DMAG was tested for radioprotection in CD2F1 mice. The results showed that orally administered 17-DMAG as a single dose of $10 \mathrm{mg} / \mathrm{kg} 24 \mathrm{~h}$ prior to ${ }^{60} \mathrm{Co} \gamma$-photon irradiation increased mouse survival by $20-25$ percentage points more than corresponding controls. The radioprotective effect of orally administered 17-DMAG is only prophylactic and protective efficacy is not dose-dependent. Most importantly, the given $10 \mathrm{mg} / \mathrm{kg}$ of $17-\mathrm{DMAG}$ delayed the onset 
A

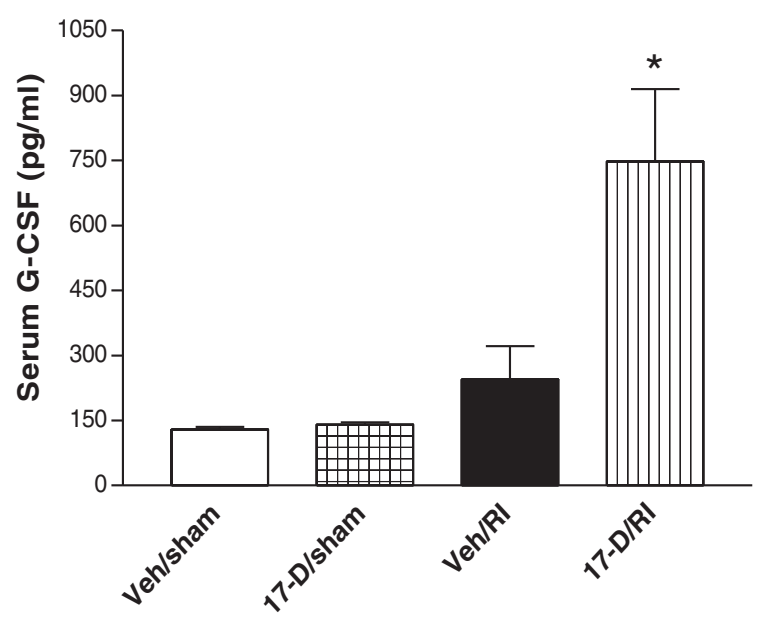

B

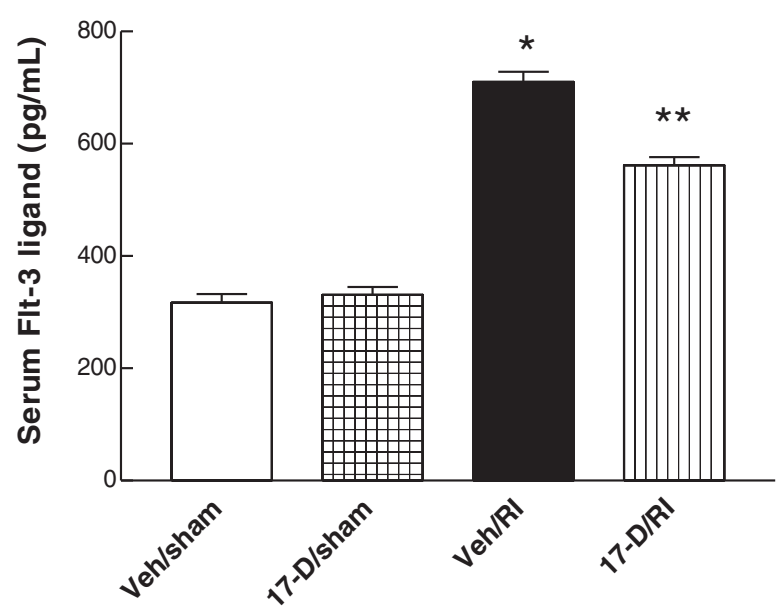

C

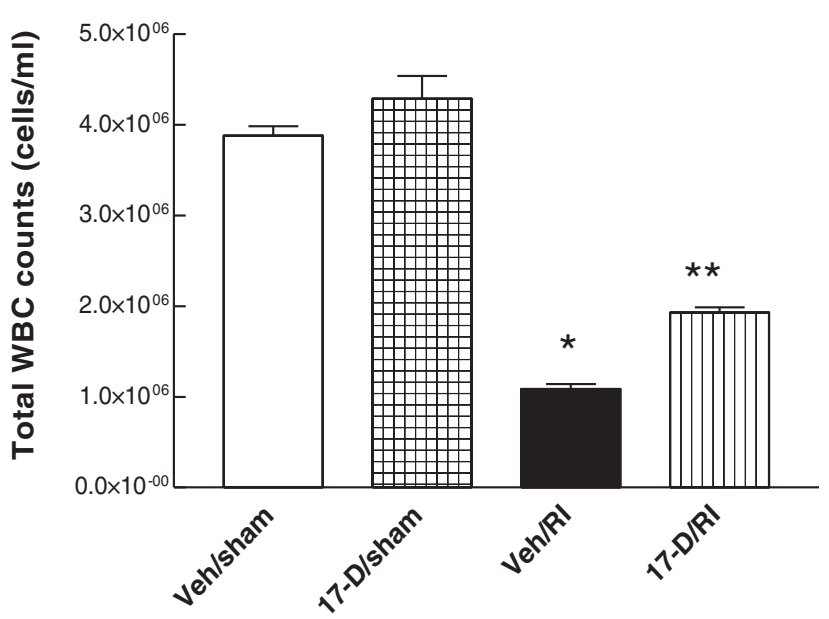

Figure 7 17-DMAG upregulated serum G-CSF, inhibited radiation-induced increases in serum Flt-3 ligand, and alleviated radiation-induced WBC depletion in blood. Mice received a single oral administration of 17-DMAG (10 mg/kg) $24 \mathrm{~h}$ before irradiation at $8.75 \mathrm{~Gy}$. Whole blood and serum were collected 30 day after irradiation. (A) Serum G-CSF (pg/ml) was detected by ELISA: * $p<0.01$ vs. Veh/sham, 17-D/sham, and Veh/RI groups, error bars indicating the SEM for five independent experiments. (B) Measurement of serum Flt-3 ligand (pg/ml) by ELISA: * $p<0.001$ vs. Veh/sham, 17-D/sham, and 17-D/RI groups; ${ }^{* *} p<0.001$ vs. Veh/sham, 17-D/sham and Veh/Rl, error bars indicating the SEM for six independent experiments. (C) WBC counts (cells/ml): * $p<0.001$ vs. Veh/sham, 17-D/sham, 17-D/Rl groups; ** $p<0.001$ vs. Veh/sham, 17-D/sham and Veh/Rl groups, error bars also indicating the SEM for six independent experiments. Veh: vehicle; 17-D: 17-DMAG; RI: radiation injury.

of mortality by 2.5 days and significantly prolonged $\mathrm{ST}_{50}$ by approximately 8 days, in comparison with vehicle control after irradiation. Meanwhile, given doses of 5, 25, and $75 \mathrm{mg} / \mathrm{kg}$ were not effective, suggesting that the oral administration of 17-DMAG may have a narrow protective window. It is not clear why the repeated dose of $10 \mathrm{mg} / \mathrm{kg}$ administered to 2-3 times did not further increase radioprotective efficacy in comparison of a single dose. The effective dose, $10 \mathrm{mg} / \mathrm{kg}$ used in this study, is in agreement with its administration in the mouse model of hemorrhagic shock [37], in which orally administered 17-DMAG at a single dose of $10 \mathrm{mg} / \mathrm{kg}$ reached the maximal effect, whereas doses of 20 , and $30 \mathrm{mg} / \mathrm{kg}$ did not further increase the efficacy of preventing hemorrhagic injury.
In this study, non-irradiated mice can tolerate an oral dose of 17-DMAG up to $75 \mathrm{mg} / \mathrm{kg}$ without causing any mortality 30 days after administration. This observation is in agreement with that reported by Egorin [8]. However, in irradiated mice, the optimal dose of orally administered $17-D M A G$ was $10 \mathrm{mg} / \mathrm{kg}$. It is unclear why increased oral doses to 25 or $75 \mathrm{mg} / \mathrm{kg}$ failed to improve 30-day survival of irradiated animals. The oral doses of 25 and $75 \mathrm{mg} / \mathrm{kg}$ (equal to 69.67 and $209.01 \mathrm{mg} / \mathrm{m}^{2} /$ day in a mouse with $25 \mathrm{~g}$ of body weight, respectively) exceeded the maximum tolerated dose (i.e., $16.1 \mathrm{mg} / \mathrm{kg} /$ day or $45 \mathrm{mg} / \mathrm{m}^{2} /$ day) of 17-DMAG in mice [38]. Therefore, 17-DMAG at these doses might lead to some potential tissue toxicity, especially hepatotoxicity, liver dysfunction, and body weight loss [39]. 


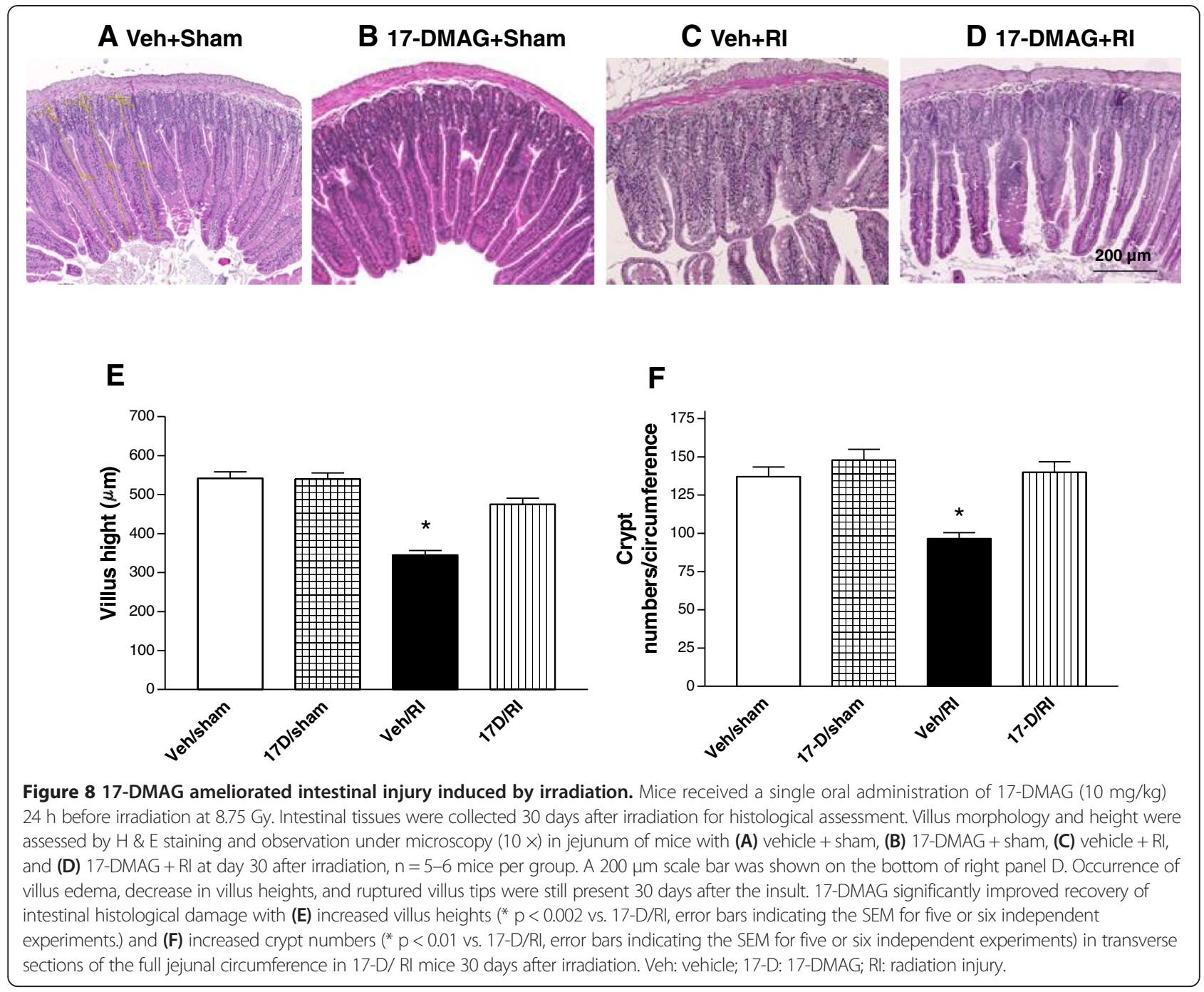

We also observed body weight loss in mice pre-treated with 17-DMAG at higher doses other than those administered with $10 \mathrm{mg} / \mathrm{kg}$ (i.e., $27.87 \mathrm{mg} / \mathrm{m}^{2} /$ day) from day 5 to day 25 after irradiation (data not shown). Other laboratory reported the selected nontoxic doses of oral 17-DMAG at $7.5-15 \mathrm{mg} / \mathrm{kg} /$ day (i.e., $20.9-41.8 \mathrm{mg} / \mathrm{m}^{2} /$ day) were employed for an antitumor study in a carcinoma mouse model [40]. Thus, it may explain why the orally administered 17-DMAG at both high doses (may be toxic to irradiated mice) was not radioprotective. We postulate that a dose-response effect of 17-DMAG at doses less than the maximum tolerated dose could still be feasible. We also postulate that pre-administration of an oral dose of $10 \mathrm{mg} / \mathrm{kg}$ for 5 consecutive days could result in 17-DMAG accumulating in liver, because it persists in this organ for $24 \mathrm{~h}$ after administration [8]. In liver and kidney tissues, 17-DMAG concentration was 10-40-fold greater than it in plasma 10-1440 min after i.v. administration in mice [41]. Therefore, the accumulated drug and its degraded products day by day in liver for 5 days might add even more harm to hepatocytes and their functions that have already been impaired by irradiation.

Orally administered 17-DMAG, however, produced a lower survival efficacy than s.c. injected 17-DMAG (56\% oral vs. $95 \%$ s.c. [20]) 30 days after irradiation. This discrepancy could be due to several factors. Firstly, the route of drug administration and the vehicle used were different. The optimal dose $(10 \mathrm{mg} / \mathrm{kg})$ for oral administration differed from the dose $(25 \mathrm{mg} / \mathrm{kg})$ given through s.c. injections. The vehicle used for orally administered 17-DMAG was 5\% dextrose, whereas the vehicle used for s.c. injected 17-DMAG was polyethylene glycol 400 (PEG-400). Secondly, 17-DMAG bioavailability was $100 \%$ by i.v., but only $50 \%$ by oral delivery in CD2F1 mice [8] so that the drug bioavailability would be expected to be higher by a s.c. injection than by an oral delivery. Thirdly, although 17-DMAG was widely distributed to all tissues, but the highest concentration of 17-DMAG was 


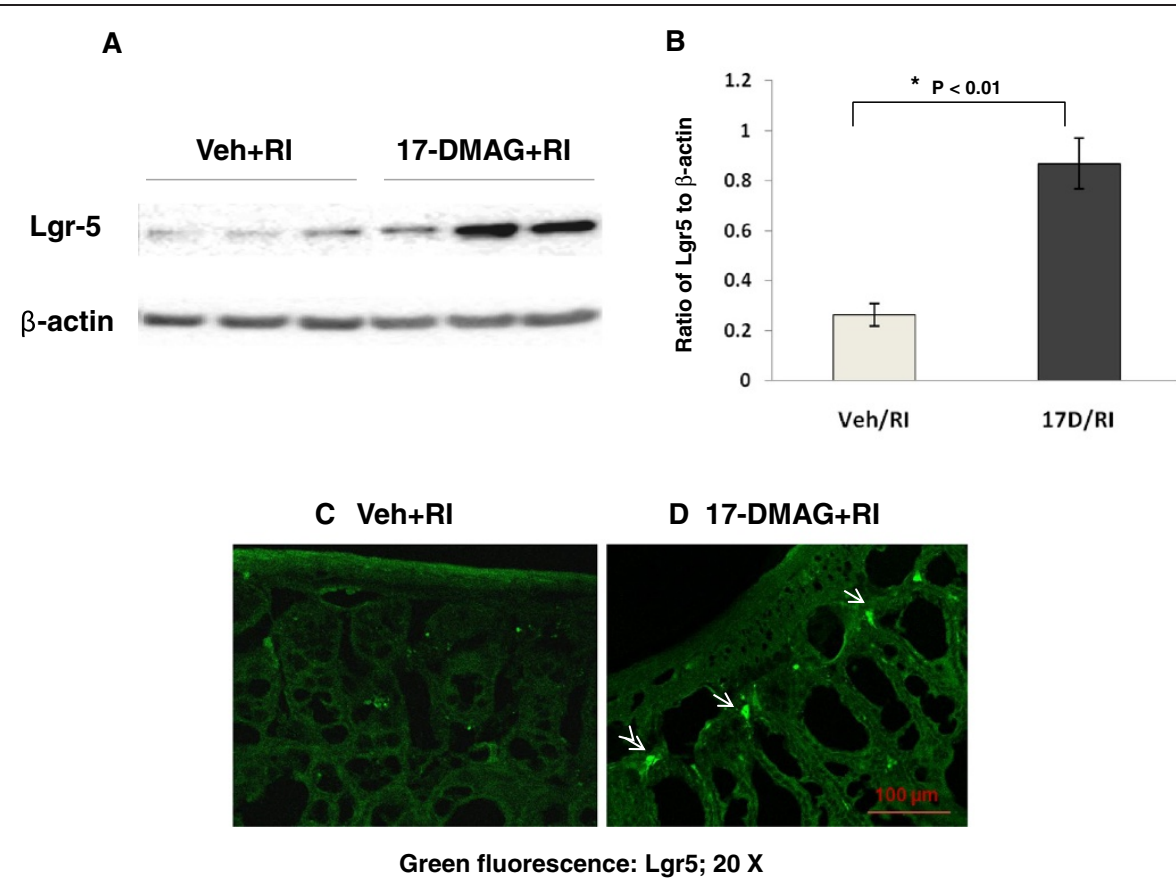

Figure 9 17-DMAG upreguateded Lgr5 expression in crypt cells. (A) Lgr5 was detected with Western blot and its expression increased in intestines of 17-DMAG-treated mice compared to vehicle-treated animals 30 days after irradiation at 8.75-Gy. (B) Densitometric quantitation of Lgr5 protein.* $p<0.01$ vs. Veh/RI group, error bars indicating the SEM for three or four independent experiments. Lgr5 (indicated by white arrows) localizing at base cells of crypts in vehicle-pretreated (C) and 17-DMAG-pretreatd mice (D) was demonstrated using immune-staining method and confocal microscope $(20 \times) 30$ days after irradiation and a $100 \mu \mathrm{m}$ scale bar was shown on the bottom. $\mathrm{N}=3-4$ mice per group.

found in the liver [8]. Orally administered 17-DMAG was initially and primarily absorbed by the gastrointestinal tract, and quickly went into liver and was much accumulated there, thereby limiting17-DMAG entering other tissues and organs. While s.c. injected 17-DMAG in PEG 400 that increased the particle size was absorbed by subcutaneous tissues and local vascular beds, and delivered to various organs through circulation without prior drug accumulation in liver. Subcutaneous tissues such as fat, in fact, can store the drug that would be released gradually because there is limited blood flow. Despite given $25 \mathrm{mg} / \mathrm{kg}$ of 17-DMAG in PEG-400 via s.c. injection, being higher than maximum tolerated dose per day, it was generally absorbed more slowly, even taking more than $24-48 \mathrm{~h}$ into blood. Thus, a greater radioprotective efficacy of s.c. injected 17-DMAG than orally administered 17-DMAG was observed.

We postulate that most of the orally administered 17-DMAG at 25 or $75 \mathrm{mg} / \mathrm{kg}$ might have been accumulated, metabolized, and degraded in the livers of sham animals. These processes would be critical to eliminate the drug and its degraded products from the body, otherwise producing potential harmful side effects or tissue toxicity in 48-72 h. In irradiated mice, the livers were incapable or limitable of performing detoxification due to impairment caused from the lethal whole-body irradiation. As a result of this failure to detoxify, the pharmacologic effects of 17-DMAG at high doses decrease or become detrimental. Only a nontoxic oral dose of $17-D M A G$ at $10 \mathrm{mg} / \mathrm{kg}$ enable to retain radioprotection.

We noticed that repeated 17-DMAG administrations at $10 \mathrm{mg} / \mathrm{kg}$ failed to further improve the mouse survival after irradiation. We hypothesize that it is possible due to degraded products of 17-DMAG accumulating in an impaired liver caused by irradiation. This accumulation of degraded products resulted in toxicity to the irradiated mice. The same explanation may also explain why orally administered 17-DMAG for 5 consecutive days before irradiation failed to improve the mouse survival after irradiation.

Post-treatment with 17-DMAG also failed to improve survival after irradiation, due to radiation-induced DNA double strand breaks (DSB) and p53 phosphorylation, which occurred within $1 \mathrm{~h}$ after irradiation. Those events were then followed by sequential activations of signal transduction pathways leading to cell death and multiple organ dysfunction and failure. We have reported that pretreatment of human $\mathrm{T}$ cells with 17-DMAG was effective in preventing DSB and p53 phosphorylation by blocking p53 interaction with Hsp 90, and p53 gene knockout cells were also resistant to irradiation [13]. This likely explains why in this presented study pretreatment with 17-DMAG is effective. Post-treatment with 17-DMAG probably would be too late to stop DSB 
and p53 phosphorylation, which would explain why the post-treatment with the drug is ineffective.

Radiation significantly reduced body weight and water consumption in CD2F1 mice (Figure 3); these observations agree with those in B6D2F1/J mice [21]. Radiation-induced facial dropsy was found in CD2F1 mice [42], C57BL/6 mice, and iNOS knockout mice, but not B6D2F1/J mice (data not shown), suggesting this observation could be strain-specific. It is highly likely that 17-DMAG inhibition on radiation-induced facial edema may involve in its activity of anti-inflammation, but more experiments will be necessary.

Radiation significantly depleted bone marrow cells and induced adipose vacuole appearance (Figure 4C). In 17-DMAG-treated mice, amelioration of bone marrow cell depletion, accelerated recovery of the cellularity, and reduced adipogenesis of bone marrow (Figure 4D) were observed accompanied by upregulation of CD34 and CD44 expression (Figure 5C), indicating that 17-DMAG could protect bone marrow cells of 30-day surviving mice after irradiation. The view is further reinforced by increased numbers of live bone marrow cells at days 7 and 15 and elevated 7AAD-negative percentage of bone marrow cells at day 15. However, how 17-DMAG exerting its radioprotection on bone marrow cells remains unknown.

Survivin is normally bound to Hsp90 in the cytoplasm [22]. It is reported that cultured SW480 cell exposed to a 4-Gy irradiation [43], the nuclear survivin was linked to DNA double-strand-break repair by interaction with members of the repair pathway. This view is supported by a study using normal healthy human peripheral blood mononuclear cells, in which 17-DMAG inhibited radiationinduced increases in $\gamma-\mathrm{H} 2 \mathrm{AX}$, a biomarker of DSB [13]. Although irradiation increased the survivin protein level at day 30 after irradiation, we think this increase is a self-defensive response which is too late to alleviate the mortality. We postulate that 17-DMAG inhibits Hsp90 resulting in the release of survivin from Hsp90 and then survivin ready for involving in the process of repairing the radiation-induced DSB.

Our survivin data agree with findings from another laboratory [44], in which 17-DMAG $(0.1-1 \mu \mathrm{g} / \mathrm{ml})$ alone elevated survivin production in vitro and rendered the cells insensitive to apoptosis. Survivin is anti-apoptotic by inhibiting various caspases [22,24]. Our laboratory reported that 17-DMAG inhibited caspase-3 and -9, leading to an inhibition of apoptosis [12,37]. It is plausible that 17-DMAG increased mouse survival after irradiation by activating the survivin pathway that may regulate $\beta$-catenin, $\mathrm{p} 53$, $\mathrm{NF}-\mathrm{kB}$, and Stat3 multiple signalings [45] and caspase-3 and -7 [24]. Further investigation of survivin regulation by 17-DMAG is warranted.

Moreover, the 17-DMAG ameliorating bone marrow damage induced by irradiation correlates with the reduction of Flt-3 ligand concentrations in serum (Figure 7B). The serum level of Flt-3 ligand has been suggested as a biomarker of radiation injury to bone marrow and a surrogate for the extent of damage to hematopoietic progenitor cells in bone marrow after ionizing irradiation [46-48]. Thus, the reduction of radiation-induced higher Flt-3 ligand concentrations is another indirect evidence to support the radioprotection of bone marrow cells by 17-DMAG. Our result on Flt-3 ligand concentrations is consistent with that in another report [46] that the concentration of serum Flt-3 ligand is reversely correlated with WBC counts in peripheral blood.

17-DMAG attenuated the radiation-induced WBC depletion (Figure 7C), which correlated with G-CSF increases in the presence of 17-DMAG (Figure 7A). G-CSF acts at all stages of neutrophil development, specifically increasing the proliferation and differentiation of neutrophils from committed progenitors [49], enhancing survival and function of mature neutrophils [50,51]. G-CSF is a cytokine and a growth factor, which possesses radioprotective properties $[52,53]$ by stimulating growth, differentiation and prevention of apoptosis of progenitor cells. Like 17-DMAG, pre-administration of alpha-tocopherol succinate $[54,55]$ and post-treatment with meloxicam [56] or 5-androstenediol [57] increased serum G-CSF concentrations within 4-24 h after injections. Alpha-tocopherol succinate induced a peak level of G-CSF within $24 \mathrm{~h}$ and a rapid fall $36 \mathrm{~h}$ after s.c. administration. Our other data from irradiated CD2F1 mice pre-treated s.c. with 17-DMAG also indicated that 17-DMAG enhanced serum G-CSF concentration as early as $4 \mathrm{~h}$ and lasted up to day 2, 10, and 15 after irradiation compared with the vehicle group (Lu et al., unpublished data). These data suggest that 17-DMAG, like other radioprotectant such as alpha-tocopherol succinate, confers radioprotection by inducing high levels of G-CSF. Other studies indicated that G-CSF not only enhanced the production of hematopoietic progenitor cells in bone marrow but also mobilized those primitive progenitors from the hematopoietic tissue into the circulation [58,59]. Therefore, 17-DMAG administration increased numbers of WBC probably mediated by the increasing G-CSF 30 days postirradiation. The present study may offer a new insight on regulation of survivin and G-CSF by 17-DMAG. However, the possibility of increased G-CSF concentrations being a consequence of hematopoietic recovery cannot be excluded.

It is known that 17-DMAG inhibits activation of the iNOS pathway in vitro [37] and in vivo [20], and the p53 pathway ex vivo [13]. Further studies should explore the inter-relationship among iNOS, p53, and survivin pathways and the regulation of G-CSF.

Radiation-induced gastrointestinal syndrome (RIGS) results from a combination of direct cytocidal effects on intestinal crypt and endothelial cells and subsequent loss 
of the mucosal barrier, leading to malabsorption, electrolyte imbalance, diarrhea, weight loss, infection, dysfunction, and final mortality. Stem cells located at the base of the crypt undergo rapid apoptosis or stop dividing temporarily or permanently after irradiation. Therefore, RIGS is due in part to the killing of clonogenic crypt cells with eventual depopulation of the intestinal villi [60].

17-DMAG attenuated the pathological alteration in villi 30 days postirradiation. Oral administration of 17-DMAG (10 mg/kg) decreased mucosal atrophy, edema and ulceration, increased the number of crypts where ISC are located, and more importantly, upregulated expression of Lgr5 (a molecular marker of ISC in intestinal crypts). The results agree with the findings in hemorrhaged jejunum [37], suggesting that 17-DMAG prevents the radiation-induced structural injury in small intestine, body weight loss, and facial edema, further improves survival of irradiated mice.

Since in hemorrhaged small intestine, 17-DMAG diminished hemorrhage-induced small intestine injury by elevating $\mathrm{Bcl}-2$ protein and inhibiting iNOS pathway, TNF- $\alpha$ production, and caspase- 3 activation [37], the possibility of 17-DMAG exerting its actions on these factors to ameliorate the radiation-induced gastrointestinal injury cannot be excluded. More studies in this regard are ongoing.

\section{Conclusion}

A single dose of orally administered 17-DMAG $(10 \mathrm{mg} / \mathrm{kg})$ as a prophylactic measure prior to irradiation was effective to increase mouse 30-day survival by protecting bone marrow and small intestine from radiation injury. The protective effects of pre-administered 17-DMAG were associated with (1) increased expression of survivin, CD34, CD44 in bone marrow and G-CSF in serum, which were correlated with attenuated bone marrow injury and WBC loss and were confirmed by the decreased Flt-3 ligand concentration in circulation; (2) up-regulated Lgr5 expression and Lgr5-positive stem cells in intestinal crypts, which promoted intestinal epithelial repairing, self-renewing and body weight recovery from irradiation-induced injury. Taken together, our results suggest that 17-DMAG appears to be an effective prophylactic radioprotectant in bone marrow cells and in intestinal crypt cells including intestinal stem cells, which contributes to enhanced survival.

\section{Materials and methods}

\section{Animals}

Male CD2F1 mice were purchased from Harlan Laboratories (Dublin, VA, USA) and used at age of 10 to 12 weeks at the time of irradiation. The mice were housed in groups of four in polycarbonate microisolator cages $(11.5 \times 7.5 \times 5$ in. $)$ with filter tops on autoclaved rodent hardwood bedding. Animal rooms were maintained at
$21 \pm 2^{\circ} \mathrm{C}, 50 \% \pm 10 \%$ humidity, and 12-h light/dark cycle. All facilities were accredited by the Association for Assessment and Accreditation of Laboratory Animal Care International. Rodent food (Harlan Teklad Rodent Diet 8604) and water were freely available for mice. All handling procedures were performed in compliance with guidelines from the National Research Council, and were approved by the Institutional Animal Care and Use Committee (IACUC) of the AFRRI.

\section{7-DMAG preparation and oral administration}

17-DMAG (LC Laboratories, Woburn, MA, USA) was prepared as previously described [37]. Briefly, 17-DMAG was freshly solubilized in 5\% Dextrose (Baxter Healthcare, Deerfield, IL, USA) on the day of the experiment. The drug was orally administered to mice at (1) a single dose of $5,10,25$, or $75 \mathrm{mg} / \mathrm{kg}$ in a volume of $0.2 \mathrm{ml} 24 \mathrm{~h}$ before irradiation; (2) a single dose of $10 \mathrm{mg} / \mathrm{kg} \mathrm{1,} \mathrm{24,} \mathrm{48,} \mathrm{or} 72 \mathrm{~h}$ prior to irradiation; (3) a single dose of $10 \mathrm{mg} / \mathrm{kg} \mathrm{1,} \mathrm{6,} \mathrm{or}$ $24 \mathrm{~h}$ after irradiation; and (4) multiple doses of $10 \mathrm{mg} / \mathrm{kg}$ $120,96,72,48$ and $24 \mathrm{~h}$ before irradiation. Vehicle groups were orally fed the same volume of $5 \%$ Dextrose.

\section{Irradiation}

Mice were restrained in well-ventilated acrylic irradiation boxes. Mice were given a dose of $8.75 \mathrm{~Gy}{ }^{60} \mathrm{Co} \gamma$ photons at a dose rate of $0.6 \mathrm{~Gy} / \mathrm{min}$ bilaterally in the AFRRI ${ }^{60} \mathrm{Co}$ Irradiation Facility. The uniformity of the field in the used part of the rack was $\pm 1 \%$. Control (sham) animals were placed into the acrylic radiation boxes but were not irradiated. The total tissue dose of radiation received was measured at the level of the abdominal core. An alanine electron-spin-resonance (ESR) dosimetry system (American Society for Testing and Materials, Standard E 1607) was used to measure dose rates (to water) in the cores of acrylic mouse phantoms. To simulate a mouse, the phantoms were three inches in length and one inch in diameter. For field mapping, all exposure rack compartments contained phantoms, and alternate phantoms contained alanine dosimeters. The ESR signals were measured using a calibration curve based on the standard calibration dosimeters (National Institute of Standards and Technology (NIST), Gaithersburg, MD, USA). The overall uncertainty in the doses given to the calibration dosimeters at NIST was approximately $1.8 \%$ at 2 standard deviations. The accuracy of the calibration curve was verified by parallel measurements of doses to selected dosimeters at AFRRI and the National Physical Laboratory, Middlesex, England, UK. Corrections were applied to the dose rates in phantoms for the decay of ${ }^{60} \mathrm{Co}$ and differences in the mass energy-absorption coefficients for water and soft tissue [61]. The day of irradiation was considered day 0 . 


\section{Animal survival, body weight, water consumption, and facial dropsy}

Sixteen mice were randomly assigned to each group. Experimental groups included: (1) 5\% Dextrose vehicle + sham (Veh/sham), (2) 17-DMAG + sham (17-D/sham), (3) $5 \%$ Dextrose vehicle + radiation injury (Veh/RI), and (4) 17-DMAG + radiation injury (17-D/RI). After irradiation, mice were returned to their home cages. Water consumption was measured with graduated water bottles daily for the first 7 days. Mouse survival, body weight, and facial dropsy were monitored for 30 days post-irradiation. At day 30 , the surviving mice were euthanized and their bloods, intestines and femurs were collected for analysis.

\section{Histological examination, bone marrow myeloid cell viability, and cell phenotype analysis}

One femur from each surviving mouse 30 days after irradiation was fixed in $10 \%$ formalin for at least $24 \mathrm{~h}$. All samples were embedded with paraffin and sectioned longitudinally for haematoxylin \& eosin (H \& E) staining. The stained slides were examined at $20 \times$ magnification under microscope (Olympus BX-61, Olympus, Japan). Bone marrow cells were flushed from the other femur of each surviving mouse 30 days after irradiation. After two washes with phosphate buffered saline (PBS) solution, cells were lysed by using lysis buffer and their proteins were extracted following a commercial extraction method (Pierce Protein Research, Rockford, IL, USA). For investigating effect of 17-DMAG on bone marrow after irradiation, bone marrow cells were also collected from mouse femora at 3, 7 and 15 days after irradiation in a separate experiment. After erythrocytes were lysed by red blood cell lysis buffer (BioLegend San Diego, CA, USA), total bone marrow cell viability from each mouse was assayed by trypan blue staining [12]. For bone marrow cells from the mice at day 15 after irradiation, cells also were labeled with 7AAD, a death marker of cells and their cell viabilities were analyzed by flow cytometry using BD FACSCalibur (BD Biosciences, San Jose, CA, USA). Cells were gated for 7AAD-positive cells and negative live cells. All antibodies and dyes were purchased from BD Biosciences.

\section{Intestinal histological and immunohistochemical assessments}

Small intestine was harvested after 30-day survival for intestinal protein expression or morphological analysis. The distal jejunum and proximal ileum were fixed for histology in 10\% formalin with PBS. Paraffin embedded gut tissues were sectioned and stained with $\mathrm{H}$ \& $\mathrm{E}$. Nanozoomer virtual microscopy (Hamamatsu Photonics, Hamamatsu, Japan) was used for measurement of the villus height and the count of crypt numbers. A minimum of 10 well-oriented villi per tissue section (at least 5 sections from each gut specimen) was measured and crypt numbers were counted in all 5 sections of each specimen.

Frozen slides of ileum were prepared and immunostained, following a previous published method [62] for expression and localization of Lgr5 in small intestine. Briefly, after fixing and blocking procedure, slides were incubated with primary antibodies, goat anti-Lgr5 IgG (Genway, SanDiego, CA, USA) 1:100 dilution for $60 \mathrm{~min}$. Slides were incubated with secondary antibodies, donkey anti-goat IgG-Alexa Fluor 488 (Invitrogen, Carlsbad, CA, USA) for $1 \mathrm{~h}$. Finally, slides were mounted with ProLong Gold Antifade, counterstained with DAPI (4',6'-diamidino-2-phenylindole; Invitrogen, Carlsbad, CA, USA), and observed under a confocal laser scanning microscope (Zeiss LSM710, Carl Zeiss MicroImaging, Thornwood, NY, USA).

\section{Western blot}

Proteins in lysates of bone marrow and gut tissues were separated by $4-12 \%$ Bis-tris gel electrophoresis and transferred onto a nitrocellulose membrane according to a standard technique for antibody detection of proteins. Primary antibodies against mouse G-CSF (BD Pharmingen, San Diego, CA, USA), CD44 (BioLegend, San Diego, CA, USA), CD34 (Santa Cruz Biotechnology, Santa Cruz, CA, USA), Lgr5 (Genway, SanDiego, CA, USA), survivin (Millipore, Temecula, CA, USA), and $\beta$-actin (Sigma, St. Louis, MO, USA) were used in immunoblotting assays, respectively.

\section{Enzyme-linked immunosorbent assay}

Murine serum levels of EPO, G-CSF, and Flt-3 ligand were measured by ELISA (R\&D Systems, Minneapolis, $\mathrm{MN}$, USA) according to the manufacturer's protocols.

\section{White blood cell counts}

Blood was collected by cardiac puncture from mice anesthetized with isoflurane inhalation and placed promptly in an ethylenediaminetetraacetic acid (EDTA)-containing tube for blood cell counts and a regular eppendorf tube for serum separation. Red blood cells in the EDTA-containing tube were lysed by RBC lysis buffer (BioLegend San Diego, CA, USA), and the remaining leukocytes were washed in $1 \%$ ammonium oxalate solution. The total number of leukocytes in $10 \mu \mathrm{l}$ of blood was counted manually in a hemocytometer.

\section{Statistical analysis}

The data of 30-day survival of mice were analyzed using Two-way analysis of variance (ANOVA). For parametric data, differences among or between groups were compared by ANOVA and Student's $t$-test, respectively, with significance at $\mathrm{p}<0.05$. Results of parametric data were presented as means \pm standard errors. 


\section{Abbreviation}

7AAD: 7-aminoactinomycin D; 17-DMAG: 17-dimethylamino-ethylamino-17demethoxygeldanamycin; CBC: Crypt base columnar; CD34, CD44: Cluster of differentiation 34, 44; DMF: Dose-modifying factor; DRF: Dose reduction factor; DSB: DNA double strand breaks; EPO: Erythropoietin; Flt-3: fms-like tyrosine kinase-3; G-CSF: Granulocyte-colony stimulating factor; Hsp90: Heat shock protein 90; iNOS: Inducible nitric oxide synthase; ISC: Intestinal stem cells; i.v.: Intravenous; LD70/30: A dose to result in 70 percent of an exposed population died within 30 days; Lgr5: Leucine-rich repeat-containing G-protein coupled receptor 5; RBC: Red blood cell; s.c.: Subcutaneous; Veh/ sham: Vehicle + sham; $S_{50}$ : Median survival time; 17-D/sham: 17-DMAG + sham; Veh/RI: Vehicle + radiation injury; 17-D/RI: 17-DMAG + radiation injury; WBC: White blood cell.

\section{Competing interests}

The authors declare that they have no competing interests. The authors alone are responsible for the content and writing of the paper. The views, opinions and findings contained in this report are those of the authors and do not reflect official policy or positions of the US Department of the Navy, the US Department of Defense, or the United States Government.

\section{Author's contributions}

$\mathrm{XL}$ carried out the experimental studies, data analysis and drafted the manuscript. DN conducted Western blot and animal experiment. DLB contributed to animal irradiation, TBE participated in animal experiment and revised the manuscript. JGK conceived the project, designed the study, reviewed and revised final manuscript. All authors read and agreed with the manuscript. The funders had no role in study design, data collection and analysis or preparation of the manuscript.

\section{Acknowledgments}

We thank Dr. Min Zhai, Ms. Joan Smith, HM1 Neil Agravante USN, Dr. Cam $\mathrm{Ha}$ and Ms. Xiang Hong Li for their technical assistance; Dr. Venkataraman Srinivasan and his IACUC administrators for IACUC monitoring; LTC Steven Tobias USA and his associated veterinary personnel for animal care; and Dr. Vitaly Nagy and his associated personnel for radiation dosimetry and radiation source operation. This study was supported by Defense Threat Reduction Agency grant H-10017-09-AR-R to JGK and grant CBMR. 03.10AR.010 to JGK.

\section{Author details}

'Radiation Combined Injury Program, Scientific Research Department, Armed Forces Radiobiology Research Institute, 8901 Wisconsin Avenue, Bethesda, MD 20889-5603, USA. ${ }^{2}$ Department of Radiation Biology, Uniformed Services University of the Health Sciences, Bethesda, MD, USA. ${ }^{3}$ Department of Medicine, Uniformed Services University of the Health Sciences, Bethesda, $M D$, USA.

Received: 30 January 2013 Accepted: 1 August 2013 Published: 16 September 2013

\section{References}

1. Whitesell L, Mimnaugh EG, De Costa B, Myers CE, Neckers LM: Inhibition of heat shock protein HSP90-pp60v-src heteroprotein complex formation by benzoquinone ansamycins: essential role for stress proteins in oncogenic transformation. Proc Natl Acad Sci USA 1994, 91:8324-8328.

2. Stebbins CE, Russo AA, Schneider C, Rosen N, Hartl FU, Pavletich NP: Crystal structure of an Hsp90-geldanamycin complex: targeting of a protein chaperone by an antitumor agent. Cell 1997, 89:239-250.

3. Jez JM, Chen JC, Rastelli G, Stroud RM, Santi DV: Crystal structure and molecular modeling of 17-DMAG in complex with human Hsp90. Chem Biol 2003, 10:361-368.

4. Kabakov AE, Kudryavtsev VA, Gabai VL: Hsp90 inhibitors as promising agents for radiotherapy. J Mol Med (Berlin, Germany) 2010, 88:241-247.

5. Li Y, Zhang T, Schwartz SJ, Sun D: New developments in Hsp90 inhibitors as anti-cancer therapeutics: mechanisms, clinical perspective and more potential. Drug Resist Update 2009, 12:17-27.

6. Kummar S, Gutierrez ME, Gardner ER, Chen X, Figg WD, Zajac-Kaye M, Chen M, Steinberg SM, Muir CA, Yancey MA, Horneffer YR, Juwara L, Melillo G, IVy SP, Merino M, Neckers L, Steeg PS, Conley BA, Giaccone G, Doroshow JH, Murgo AJ: Phase I trial of 17-dimethylaminoethylamino-17-demethoxygeldanamycin
(17-DMAG), a heat shock protein inhibitor, administered twice weekly in patients with advanced malignancies. Euro J Cancer 2010, 46:340-347.

7. Ramanathan RK, Egorin MJ, Erlichman C, Remick SC, Ramalingam SS, Naret C, Holleran JL, TenEyck CJ, Ivy SP, Belani CP: Phase I pharmacokinetic and pharmacodynamic study of 17-dimethylaminoethylamino-17demethoxygeldanamycin, an inhibitor of heat-shock protein 90 , in patients with advanced solid tumors. J Clin Oncol 2010, 28:1520-1526.

8. Egorin MJ, Lagattuta TF, Hamburger DR, Covey JM, White KD, Musser SM, Eiseman JL: Pharmacokinetics, tissue distribution, and metabolism of 17-(dimethylaminoethylamino)-17-demethoxygeldanamycin (NSC 707545) in CD2F1 mice and Fischer 344 rats. Cancer Chemother Pharmacol 2002, 49:7-19.

9. Rao R, Lee P, Fiskus W, Yang Y, Joshi R, Wang Y, Buckley K, Balusu R, Chen J, Koul S, Joshi A, Upadhyay S, Tao J, Sotomayor E, Bhalla KN: Co-treatment with heat shock protein 90 inhibitor 17-dimethylaminoethylamino-17demethoxygeldanamycin (DMAG) and vorinostat: a highly active combination against human mantle cell lymphoma (MCL) cells. Cancer Biol \& Ther 2009, 8:1273-1280.

10. Kamal A, Thao L, Sensintaffar J, Zhang L, Boehm MF, Fritz LC, Burrows FJ: A high affinity conformation of Hsp90 confers tumour selectivity on Hsp90 inhibitors. Nature 2003, 425:407-410.

11. Whitesell L, Lindquist SL: HSP90 and the chaperoning of cancer. Nat ReV Cancer 2005, 5:761-772.

12. Kiang JG, Smith JT, Agravante NG: Geldanamycin analog 17-DMAG inhibits iNOS and caspases in gamma-irradiated human $T$ cells. Radiat Res 2009, 172:321-330.

13. Fukumoto R, Kiang JG: Geldanamycin analog 17-DMAG limits apoptosis in human peripheral blood cells by inhibition of p53 activation and its interaction with heat shock protein $90 \mathrm{kDa}$ after ionizing radiation. Radiat Res 2011, 176:333-345.

14. Mettler FA Jr, Voelz GL: Major radiation exposure-what to expect and how to respond. N Eng J Med 2002, 346:1554-1561.

15. Coleman CN, Stone HB, Moulder JE, Pellmar TC: Modulation of radiation injury. Science 2004, 304:693-694.

16. Moulder JE: Post-irradiation approaches to treatment of radiation injuries in the context of radiological terrorism and radiation accidents: a review. Int J Radiat Biol 2004, 80:3-10.

17. Wilson JW, Cucinotta FA, Shinn JL, Simonsen LC, Dubey RR, Jordan WR, Jones TD, Chang CK, Kim MY: Shielding from solar particle event exposures in deep space. Radiat Res 1999, 30:361-382.

18. Wambi CO, Sanzari JK, Sayers CM, Nuth M, Zhou ZZ, Davis J, Finnberg N, Lewis-Wambi JS, Ware JH, El-Deiry WS, Kennedy AR: Protective effects of dietary antioxidants on proton total-body irradiation-mediated hematopoietic cell and Animal survival. Radiat Res 2009, 172:175-186.

19. Li XH, Fu D, Latif NH, Mullaney CP, Ney PH, Mog SR, Whitnall MH, Srinivasan V, Xiao M: Delta-tocotrienol protects mouse and human hematopoietic progenitors from gamma-irradiation through extracellular signal-regulated kinase/mammalian target of rapamycin signaling. Haematologica 2010, 95:1996-2004.

20. Kiang JG: Geldanamycin analog 17-DMAG confers radioprotection by inhibiting apoptosis and autophagy. In Proceedings of 55th Radiation Research Society Annual Meeting: 4-7 October 2009; Savannah GA. Edited by Radiation Research Society. Savannah, GA: Allen Press; 2009:77.

21. Kiang JG, Garrison BR, Burns TM, Zhai M, Dews IC, Ney PH, Cary LH, Fukumoto R, Cary LH, Elliott TB, Ledney GD: Wound trauma alters ionizing radiation dose assessment. Cell Biosci 2012, 2:20.

22. Brandt GE, Blagg BS: Alternate strategies of Hsp90 modulation for the treatment of cancer and other diseases. Curr Top Med Chem 2009, 9:1447-1461.

23. Leung CG, Xu Y, Mularski B, Liu H, Gurbuxani S, Crispino JD: Requirements for survivin in terminal differentiation of erythroid cells and maintenance of hematopoietic stem and progenitor cells. J Exp Med 2007, 204:1603-1611.

24. Tamm I, Wang Y, Sausville E, Scudiero DA, Vigna N, Oltersdorf T, Reed JC: IAP-family protein survivin inhibits caspase activity and apoptosis induced by Fas (CD95), Bax, caspases, and anticancer drugs. Cancer Res 1998, 58:5315-5320.

25. Williams GT, Smith CA, Spooncer E, Dexter TM, Taylor DR: Haemopoietic colony stimulating factors promote cell survival by suppressing apoptosis. Nature 1990, 343:76-79.

26. Wodnar-Filipowicz A, Lyman SD, Gratwohl A, Tichelli A, Speck B, Nissen C: Flt3 ligand level reflects hematopoietic progenitor cell function in 
aplastic anemia and chemotherapy-induced bone marrow aplasia. Blood 1996, 88:4493-4499.

27. Molyneux G, Gibson FM, Whayman M, Turton JA: Serum Flt-3 ligand in a busulphan-induced model of chronic bone marrow hypoplasia in the female CD-1 mouse. Int J Exp Path 2008, 89:159-170.

28. Fang J, Menon M, Kapelle W, Bogacheva O, Bogachev O, Houde E, Browne S, Sathyanarayana P, Wojchowski DM: EPO modulation of cell-cycle regulatory genes, and cell division, in primary bone marrow erythroblasts. Blood 2007, 110:2361-2370.

29. Kiang JG, Jiao W, Cary L, Mog SR, Elliott TB, Pellmar TC, Ledney GD: Wound trauma increases radiation-induced mortality by increasing iNOS, cytokine concentrations, and bacterial infections. Radiat Res 2010, 173:319-332.

30. Withers HR, Elkind MM: Microcolony survival assay for cells of mouse intestinal mucosa exposed to radiation. Int J Radiat Biol Relat Stud Phys Chem Med 1970, 17:261-267.

31. Barker $N$, van Es JH, Kuipers J, Kujala P, van den Born M, Cozijnsen M, Haegebarth A, Korving J, Begthel H, Peters PJ, Clevers H: Identification of stem cells in small intestine and colon by marker gene Lgr5. Nature 2007, 449:1003-1007.

32. Yan KS, Chia LA, Li X, Ootani A, Su J, Lee JY, Su N, Luo Y, Heilshorn SC, Amieva MR, Sangiorgi E, Capecchi MR, Kuo CJ: The intestinal stem cell markers Bmi1 and Lgr5 identify two functionally distinct populations. Proc Natl Acad Sci USA 2012, 109:466-471.

33. Bull EE, Dote H, Brady KJ, Burgan WE, Carter DJ, Cerra MA, Oswald KA, Hollingshead MG, Camphausen K, Tofilon PJ: Enhanced tumor cell radiosensitivity and abrogation of $\mathrm{G} 2$ and $\mathrm{S}$ phase arrest by the Hsp90 inhibitor 17-(dimethylaminoethylamino)-17-demethoxygeldanamycin. Clin Cancer Res 2004, 10:8077-8084.

34. Camphausen K, Tofilon PJ: Inhibition of HSP90: a multi-target approach to radiosensitization. Clin Cancer Res 2007, 13:4326-4330.

35. Harrison EM, Sharpe E, Bellamy CO, McNally SJ, Devey L, Garden OJ, Ross JA, Wigmore SJ: Heat shock protein 90 -binding agents protect renal cells from oxidative stress and reduce kidney ischemia reperfusion injury. Am J Physiol Renal Physiol 2008, 295:F397-F405.

36. Naito AT, Okada S, Minamino T, Iwanaga K, Liu ML, Sumida T, Nomura S, Sahara N, Mizoroki T, Takashima A, Akazawa H, Nagai T, Shiojima I, Komuro I: Promotion of CHIP mediated p53 degradation protects the heart from ischemic injury. Circ Res 2010, 106:1692-1702.

37. Kiang JG, Agravante NG, Smith JT, Bowman PD: 17-DMAG diminishes hemorrhage-induce small intestine injury by elevating $\mathrm{Bcl}-2$ protein and inhibiting iNOS pathway, TNF-a increase, and caspase-3 activation. Cell Biosci 2011, 1:21.

38. Borgel SD, Carter JP, Sausville EA, Holliingshead MG: The impact of tumor location on the activity of 17-DMAG (NSC-707545), a water soluble geldanamycin analog. Clin Cancer Res 2003, 9:6215s.

39. Glaze ER, Lambert AL, Smith AC, Page JG, Johnson WD, McCormick DL, Brown AP, Levine BS, Covey JM, Egorin MJ, Eiseman JL, Holleran JL, Sausville EA, Tomaszewski JE: Preclinical toxicity of a geldanamycin analog, 17-(dimethylaminoethylamino)-17-demethoxygeldanamycin (17-DMAG), in rats and dogs: potential clinical relevance. Cancer Chemother Pharmacol 2005, 56:637-47.

40. Hollingshead M, Alley M, Burger AM, Borgel S, Pacula-Cox C, Fiebig HH, Sausville EA: In vivo antitumor efficacy of 17-DMAG (17-dimethylaminoethylamino-17demethoxygeldanamycin hydrochloride), a water-soluble geldanamycin derivative. Cancer Chemother Pharmacol 2005, 56:115-125.

41. Eiseman JL, Lan J, Lagattuta TF, Hamburger DR, Joseph E, Covey JM, Egorin MJ: Pharmacokinetics and pharmacodynamics of 17-demethoxy 17-[[(2-dimethylamino) ethyl] amino] geldanamycin (17DMAG, NSC 707545) in C.B-17 SCID mice bearing MDA-MB-231 human breast cancer xenografts. Cancer Chemother Pharmacol 2005, 55:21-32.

42. Kiang JG, Fukumoto R, Gorbunov NV: Lipid peroxidation after ionizing irradiation leads to apoptosis and autophagy. In origins of Lipid Peroxidation. 1st edition. Edited by Angel C. ; 2012:261-278. Tech Open Access Publisher (www.intechweb.org) Croatia.

43. Capalbo G, Dittmann K, Weiss C, Reichert S, Hausmann E, Rődel C, Rődel F: Radiation-induced survivin nuclear accumulation is linked to DNA damage repair. Int J Radiat Oncol Biol Phys 2010, 77:226-234.

44. Zhao X, Cao M, Joy J, Liu JJ, Zhu H, Nelson DR, Liu C: Reactive oxygen species is essential for cycloheximide to sensitize lexatumumab-induced apoptosis in hepatocellular carcinoma cells. PLoS One 2011, 6:e16966.
45. Zhang M, Yang J, Li F: Transcriptional and posttranscriptional controls of survivin in cancer cells: Essential interfaces for developing novel approaches for cancer treatment. J Exp Clin Cancer Res 2006, 25:391-402.

46. Bertho JM, Demarquay C, Frick J, Joubert C, Arenales S, Jacquet N, SorokineDurm I, Chau Q, Lopez M, Gourmelon P: Level of Flt3-ligand in plasma: a possible new bio-indicator for radiation-induced aplasia. Int J Radiat Biol 2001, 77:703-712.

47. Huchet A, Belkacemi Y, Frick J, Prat M, Muresan-Kloos I, Altan D, Chapel A, Gorin NC, Gourmelon P, Bertho JM: Plasma Flt-3 ligand concentration correlated with radiation- induced bone marrow damage during local fractionated radiotherapy. Int J Radiat Oncol Biol Phys 2003, 57:508-515.

48. Prat M, Demarquay C, Frick J, Thierry D, Gorin NC, Bertho JM: Radiationinduced increase in plasma Flt3 ligand concentration in mice: evidence for the implication of several cell types. Radiat Res 2005, 163:408-417.

49. Bociek RG, Armitage JO: Hematopoietic growth factors. CA: Cancer J Clinicians 1996, 46:165-184.

50. Gerber A, Struy H, Weiss G, Lippert H, Ansorge S, Schulz HU: Effect of granulocyte colony-stimulating factor treatment on ex vivo neutrophil functions in nonneutropenic surgical intensive care patients. Journal Interferon Cytokine Res 2000, 20:1083-1090.

51. Wenisch C, Werkgartner T, Sailer H, Patruta S, Krause R, Daxboeck F, Parschalk B: Effect of preoperative prophylaxis with filgrastim in cancer neck dissection. Eur J Clin Inv 2000, 30:460-466.

52. Neta R, Oppenheim JJ, Douches SD: Interdependence of the radioprotective effects of human recombinant interleukin 1 alpha, tumor necrosis factor alpha, granulocyte colony stimulating factor, and murine recombinant granulocyte-macrophage colony stimulating factor. J Immunol 1988, 140:108-111.

53. Uckun FM, Souza L, Waddick KG, Wick M, Song CW: In vivo radioprotective effects of recombinant human granulocyte colony-stimulating factor in lethally irradiated mice. Blood 1990, 5:638-645.

54. Singh VK, Shafran RL, Jackson WE III, Seed TM, Kumar KS: Induction of cytokines by radioprotective tocopherol analogs. Exp Mol Pathol 2006, 81:55-61.

55. Singh VK, Brown DS, Kao ZC: Alpha-tocopherol succinate protects mice from gamma-radiation by induction of granulocyte-colony stimulating factor. Int J Radiat Biol 2010, 86:12-21.

56. Hofer M, Pospisil M, Znojil V, Hola J, Vacek A, Streitova D: Meloxicam, an inhibitor of cyclooxygenase-2, increases the level of serum G-CSF and might be usable as an auxiliary means in G-CSF therapy. Physiol Res 2008, 57:307-310.

57. Singh VK, Shafran RL, Inal CE, Jackson WE III, Whitnall MH: Effects of wholebody gamma irradiation and 5-androstenediol administration on serum G-CSF. Immunopharmacol Immunotoxicol 2005, 27:521-534.

58. Herbert KE, Walkley CR, Winkler IG, Hendy J, Olsen GH, Yuan YD, Chandraratna RA, Prince HM, Levesque JP, Purton LE: Granulocyte colony-stimulating factor and a RARalpha specific agonist, VTP195183, synergize to enhance the mobilization of hematopoietic progenitor cells. Transplantation 2007, 83:375-384.

59. Hermans MH, van de Geijn GJ, Antonissen C, Gits J, van Leeuwen D, Ward AC, Touw IP: Signaling mechanisms coupled to tyrosines in the granulocyte colony-stimulating factor receptor orchestrate G-CSF- induced expansion of myeloid progenitor cells. Blood 2003, 101:2584-2590.

60. Bhanja P, Saha S, Kabarriti R, Liu L, Roy-Chowdhury N, Roy-Chowdhury J, Sellers RS, Alfieri AA, Guha C: Protective role of R-spondin1, an intestinal stem cell growth factor, against radiation-induced gastrointestinal syndrome in mice. PLOS ONE 2009, 4:e8014.

61. Day RM, Barshishat-Kupper M, Mog SR, McCart EA, Prasanna PG, Davis TA, Landauer MR: Genistein protects against biomarkers of delayed lung sequelae in mice surviving high-dose total body irradiation. $J$ Radiat Res 2008, 49:361-372.

62. Lu X, Li Y, Simovic MO, Peckham R, Wang Y, Tsokos GC, Dalle Lucca JJ: Decay-accelerating factor attenuates $C$-reactive protein-potentiated tissue injury after mesenteric ischemia/reperfusion. J Surg Res 2011, 167:e103-15.

doi:10.1186/2045-3701-3-36

Cite this article as: Lu et al:: Radioprotective effects of oral

17-dimethylaminoethylamino-17-demethoxygeldanamycin in mice: bone marrow and small intestine. Cell \& Bioscience 2013 3:36. 